\begin{tabular}{|c|l|}
\hline Title & $\begin{array}{l}\text { Expression of cyclooxygenase 2 and prostaglandin receptor EP4b mRNA in the ovary of the medaka fish, Oryzias } \\
\text { latipes: Possible involvement in ovulation }\end{array}$ \\
\hline Author(s) & Fujimori, Chika; Ogiwara, Katsueki; Hagiwara, A kane; Rajapakse, Sanath; Kimura, A tsushi; Takahashi, Takay uki \\
\hline Citation & $\begin{array}{l}\text { Molecular and Cellular Endocrinology, 332(1-2), 67-77 } \\
\text { https://doi.org/10.1016/.mce.2010.09.015 }\end{array}$ \\
\hline Issue Date & 2011-01-30 \\
\hline Doc URL & http://hdl.handle.net/2115/45012 \\
\hline Type & article(author version) \\
\hline File Information & MCE332-1-2_67-77.pdf \\
\hline
\end{tabular}

Instructions for use 


\title{
Expression of cyclooxygenase-2 and prostaglandin receptor EP4b mRNA in the ovary of the medaka fish, Oryzias latipes: Possible involvement in ovulation
}

\author{
Chika Fujimori $^{\text {a }}$, Katsueki Ogiwara ${ }^{\text {a }}$, Akane Hagiwara ${ }^{a}$, Sanath Rajapakse \\ Atsushi Kimura ${ }^{a}$, and Takayuki Takahashi ${ }^{{ }^{*}}$
}

${ }^{\mathrm{a}}$ Laboratory of Reproductive and Developmental Biology, Faculty of Science, Hokkaido University, Sapporo 060-0810, Japan

${ }^{\mathrm{b}}$ Department of Molecular Biology and Biotechnology, Faculty of Science, University of Peradeniya, Peradeniya, Sri Lanka

${ }^{*}$ Corresponding author:

Takayuki Takahashi, Laboratory of Reproductive and Developmental Biology, Faculty of Science, Hokkaido University, Sapporo 060-0810, Japan

Phone: 81-11-706-2748 Fax: 81-11-706-4851 E-mail: ttakaha@sci.hokudai.ac.jp 
Key words: prostaglandin $E_{2}$, cyclooxygenase-2, EP receptor, gene expression, ovulation, medaka

\section{ABSTRACT}

In vitro ovulation of mature medaka ovarian follicles was inhibited by inhibitors of cyclooxygenase (COX) or by an antagonist of the prostaglandin $\mathrm{E}_{2}$ receptor (EP). Of the three medaka COX genes, ptgs2 was most dominantly expressed in the fish ovary. The ptgs2 transcript was detected in all sizes of growing follicles. In a 24-h spawning cycle, large-sized follicles contained ptgs2 mRNA at a fairly constant level. The levels of COX enzyme activity and prostaglandin $\mathrm{E}_{2}$ were also constant in the large-sized follicles during the spawning cycle. The expression of prostaglandin $\mathrm{E}_{2}$ receptor EP4b (ptger4b) mRNA was drastically upregulated in the large-sized follicles as the ovulation time approached. The current results indicate that prostaglandin $E_{2}$, which might be produced by COX-2, is involved in the ovulation of medaka, and that EP4b is likely the receptor responsible for exerting the action of prostaglandin $E_{2}$ in the process. 


\section{Introduction}

Prostaglandins (PGs), which are biologically important chemical substances exerting their effects by binding to specific cell surface receptors, play roles in a wide range of physiological processes (Simmons et al., 2004; Sugimoto and Narumiya, 2007). These processes include platelet aggregation, thermoregulation, wound healing, water balance, glomerular filtration, and homeostasis. PGs are also thought to be crucial factors for the normal function of the reproductive organs. For example, ovulation, the process by which a mature fertilizable ovum is liberated from the ovarian follicle (Espey and Richards, 2006), is considered analogous to proinflammatory responses (Espey, 1994; Richards et al., 2002), and thus the role of PGs in this process has been a subject of intensive investigation (Orczyk and Berhman, 1972; Armstrong, 1981; Murdoch et al., 1993; Espey and Richards, 2006). The current understanding of ovulation in mammals is that the cascade of ovarian gene expression that induces local inflammation results in follicle rupture via proteolytic disintegration of the connective tissue elements of the follicle wall and the expansion of the cumulus oocyte complex (COC) associated with production of a specialized extracellular matrix (ECM) (Espey and Richards, 2006). Each of these processes is critical for successful ovulation. Recent studies have demonstrated the role of $\mathrm{PGE}_{2}$, the PG species that is most abundantly present in ovulating follicles of the mammalian ovary (LeMaire et al., 1973; LeMaire et al., 1975), in COC expansion (Hizaki et al., 1999; Richards et al., 2002). In contrast, the functions of $\mathrm{PGE}_{2}$ in follicle rupture during ovulation are not fully understood.

Like that in mammalian species, ovarian PG synthesis in non-mammalian vertebrates is known to occur during spontaneous or artificially-induced ovulation. In some teleosts, 
indomethacin, which is a non-selective inhibitor of the PG-producing enzyme cyclooxygenase (COX), has been reported to effectively block ovulation (Cetta and Goetz, 1982; Patino et al., 2003; Lister and Van Der Kraak, 2008). Further, other investigations have provided evidence that PGs induce in vivo and in vitro ovulation (Jalabert and Szölösi, 1975; Stacey and Pandey, 1975; Goetz and Theofan, 1979; Kagawa and Nagahama, 1981; Goetz and Nagahama, 1985; Pankhurst, 1985; Kagawa et al., 2003; Lister and Van Der Kraak, 2008). These reports indicate that PGs play an important role during ovulation in oviparous species. Possible involvement of PGs in ovulation has also been documented for amphibians (Schuetz, 1986; Chang et al., 1995; Chang et al., 1997; Ramos et al., 2008: Sena and Liu, 2008).

PGs are formed through the sequential actions of COX and specific PG synthases. It is well established that the former enzyme plays a key regulatory role in PG synthesis. Previous studies and available genomic sequence databases indicate that, like mammalian species, non-mammalian vertebrates have two paralogues of COX, a constitutive (COX-1) and an inducible enzyme (COX-2). Interestingly, teleosts possess additional copies of COX-1 and/or COX-2 that are thought to be the result of a teleost-specific genome duplication and subsequent genome loss event (Järving et al., 2004; Ishikawa and Herschman, 2007; Ishikawa et al., 2007; Havird et al., 2008). For example, the zebrafish genome contains one COX-1 gene (ptgs1) and two functional COX-2 genes (ptgs2a and ptgs2b), while the Japanese medaka (Oryzias latipes) has two COX-1 genes (ptgs1a and ptgs1b) and one COX-2 gene (ptgs2).

$\mathrm{PGE}_{2}$ exerts its actions by acting on a group of G-protein-coupled receptors. In mammals, four different $\mathrm{PGE}_{2}$ receptors, designated subtypes EP1, EP2, EP3, and EP4, 
have been identified to date, and are expected to give rise to the functional specificity of $\mathrm{PGE}_{2}$ in different tissues (Hata and Breyer, 2004; Sugimoto and Narumiya, 2007). The structures, ligand binding and signal transduction properties, tissue and cellular distribution, and physiological functions of these EP subtypes have been defined. On the other hand, only a few studies dealing with EP receptors of non-mammalian species have been published. EP4 was demonstrated to be critically involved in gastrulation during embryogenesis in zebrafish (Cha et al., 2006) and in T cell precursor development in the thymus of the fish embryo (Villablanca et al., 2007). More recently, expression of EP2 and EP4 in the tissues of chicken and their activation by $\mathrm{PGE}_{2}$ have been reported (Kwok et al., 2008).

The medaka fish, Oryzias latipes, is a small egg-laying freshwater teleost that has advantages for use in various studies, including developmental, reproductive, and molecular genetic studies (Iwamatsu et al., 1988; Nagahama et al., 1994; Ozato and Wakamatsu, 1994; Ishikawa, 2000; Wittbrodt et al., 2002; Kasahara et al., 2007). This non-mammalian vertebrate species is particularly attractive to researchers conducting ovarian function studies because of the manageable cyclicity of ovarian activity in the mature medaka fish. During the reproductive season, the medaka ovary contains oocytes in all phases of oogenesis. Oocytes can be grossly divided into five phases and further into ten stages, based on major morphological characteristics of developing oocytes and follicles (Iwamatsu et al., 1988). The fish also spawns daily within $1 \mathrm{~h}$ of the onset of light for a number of consecutive days when kept in the laboratory under a constant long photoperiod of $14 \mathrm{~h}$-light $/ 10 \mathrm{~h}$-dark at $26-28^{\circ} \mathrm{C}$. This enables us to determine the timing of a sequential process of spawning, such as completion of vitellogenesis, breakdown of the germinal 
vesicle and ovulation (Iwamatsu, 1978). The endocrine background for the ovarian cyclicity has been previously elucidated (Nagahama, 1994). Unlike fully-grown mammalian follicles, the follicle layer of growing and fully-grown follicles of the medaka consists of a single layer of granulosa cells surrounding an oocyte, a single layer of theca cells associated with a single layer of outermost ovary epithelial cells, and a basement membrane between the granulosa and theca cell layer (Pendergrass and Schroeder, 1976; Iwamatsu and Ohta, 1989). Only fully-grown follicles with a large oocyte (about $1 \mathrm{~mm}$ in diameter) ovulate. Ovulation in the medaka is also presumed to be accompanied by the destruction of ECM proteins present in the follicle layer of ovulating follicles.

We previously reported that follicle rupture during ovulation in the medaka ovary involves the cooperation of at least three matrix metalloproteinases (MMPs), together with the tissue inhibitor of metalloproteinase-2b protein (Ogiwara et al., 2005). To the best of our knowledge, the medaka is the only species in which the molecular mechanism of follicle rupture during ovulation is well documented at the present time. Taking advantage of this fact, we could effectively approach the problem of the involvement of PGs in the ovulatory process using this species. In a preliminary experiment, we found that COX inhibitors suppressed the in vitro ovulation of medaka ovarian follicles, indicating the relevance of the fish for solving the problem in question. However, there have been no studies addressing the PG-generating system in the medaka ovary. In the present study, we therefore examined the expression of COX and EP genes in the ovary of the mature medaka. Our data indicate that the fish ovary expresses ptgs $2 \mathrm{mRNA}$ at an overwhelmingly greater level than ptgs1a or ptgs1b mRNA. In addition, we found that, among EP genes expressed in the fish ovary, the expression of ptger $4 b$ (the gene for the EP4b receptor) was drastically 
induced in the large-sized follicles as the time of ovulation approached. These data, together with other results obtained in this study, suggest that COX-2/EP4b is involved in ovulation of the medaka.

\section{Materials and methods}

\subsection{Animals and tissues}

Individuals of the mature orange-red variant of medaka (Oryzias latipes) were purchased from a local dealer, and were kept in indoor tanks under artificial reproductive conditions (photoperiod, 10-h dark/14-h light; temperature, $27^{\circ} \mathrm{C}$ ). After becoming acclimated to the conditions, mature female fish ovulated in vivo each day at the start of the light period. In this study, the start of the light period was designated as ovulation hour 0 . Ovaries and ovarian follicles were isolated for experiments at various time points. Ovarian follicles were staged as described previously (Iwamatsu et al., 1988) into small-sized ( $<0.5$ $\mathrm{mm}$ in diameter, stages I-VI), medium-sized (0.5-1.0 mm, stages VII-VIII), and large-sized $(>1.0 \mathrm{~mm}$, stages IX-X) follicles. Other tissues were obtained from the fish at $3 \mathrm{~h}$ after ovulation. The experimental procedures used in this study were approved by the Institutional Animal Use and Care Committee at Hokkaido University.

\subsection{In vitro ovulation and effects of the COX inhibitor and $P G E_{2}$ receptor antagonist}

Mature female medaka fish spawning on a 24-h cycle were used. The ovaries were removed at an intermediate time point (-12 h) of ovulation. Large-sized ovarian follicles were immediately isolated by using forceps under a dissecting microscope and were then transferred into 90\% medium 199 solution (Earle’s medium 199; Dainippon-Sumitomo 
Seiyaku, Osaka, Japan) containing $5 \mu \mathrm{g} / \mathrm{ml}$ gentamycin, adjusted to $\mathrm{pH} 7.4$ with $\mathrm{NaHCO}_{3}$. About 10 follicles were cultured at $26-27^{\circ} \mathrm{C}$ in $1 \mathrm{ml}$ of culture medium by using a $1.9 \mathrm{~cm}^{2}$ tissue-culture dish. Under the in vitro condition, follicles started to ovulate at the expected time of ovulation $(0 \mathrm{~h})$ and completed ovulation in the next $6 \mathrm{~h}$. Therefore, the number of oocytes that had successfully ovulated was counted $6 \mathrm{~h}$ after the expected ovulation time. The ovulation rate was defined as the percentage of ovulated follicles. To examine the effects of indomethacin (INDO) (known as a non-selective inhibitor for mammalian COX) or GW627368X (known as an antagonist for $\mathrm{PGE}_{2}$ receptor EP4) on the in vitro ovulation, the follicles were incubated in the above medium containing various concentrations of the substances. As controls, the follicles were incubated in medium containing ethanol (for INDO) or DMSO (for GW627368X). Indomethacin was obtained from Sigma-Aldrich (St. Louis, MO). GW627368X was purchased from Cayman Chemicals (Ann Arbor, MI). In some experiments, follicles were incubated in the presence of both INDO and PGE 2 . Sigma-Aldrich).

\subsection{RNA isolation, reverse transcription (RT) and polymerase chain reaction (PCR)}

Total RNA samples were isolated from the tissues, ovarian follicles, and cultured follicular cells using Isogen (Nippon Gene, Tokyo, Japan) according to the manufacturer's instructions, and the amount and purity were determined by spectrophotometry. Reverse transcription (RT) was performed with the RNA using a SuperScript III First-Strand Synthesis System (Invitrogen, Carlsbad, CA). PCR amplification was performed in a volume of $10 \mu \mathrm{l}$ that consisted of RT reaction, $1 \times$ PCR buffer, $0.2 \mathrm{mM}$ of each dNTP, 2.5 
$\mathrm{mM} \mathrm{MgCl}_{2}, 0.2 \mu \mathrm{M}$ of each primer, and $0.5 \mathrm{U}$ Taq polymerase. The primers used in the RT-PCR are shown in Table 1.

\section{4. cDNA cloning of medaka COX-2}

A gene-specific sense and antisense primer for cloning were designed using the Ensembl genome browser (http://www.ensembl.org/Oryzias_latipes/Info/Index). To obtain a 2403-bp ptgs2 fragment, RT-PCR was conducted with KOD plus DNA polymerase (Toyobo, Osaka, Japan), using medaka ovary total RNA isolated at 3 h before ovulation. The primers used were COX2S1 and COX2AS1 (Table 1). The PCR conditions were 2 min at $94^{\circ} \mathrm{C}$, followed by 30 cycles of 15 sec at $94^{\circ} \mathrm{C}, 30 \mathrm{sec}$ at $60^{\circ} \mathrm{C}$, and $3 \mathrm{~min}$ at $68^{\circ} \mathrm{C}$. A fragment was cloned into pBluescript II KS(-) vector (Stratagene, La Jolla, CA) and sequenced.

The nucleotide sequences of the upstream region of the 87-bp cDNA were obtained by the 5'-RACE method (Frohman et al., 1988) using the 5'-RACE System for Rapid Amplification of cDNA Ends (Life Technologies, Rockville, MD) according to the manufacturer's protocol. The primers used were COX2AS2 (for RT), COX2AS3 (for the first PCR), and COX2AS4 (for the second PCR) (Table 1). Two rounds of PCR reactions were performed. The first PCR conditions were as follows: $94^{\circ} \mathrm{C}$ for $3 \mathrm{~min}$, followed by 35 cycles of $30 \mathrm{sec}$ at $94^{\circ} \mathrm{C}, 30 \mathrm{sec}$ at $55^{\circ} \mathrm{C}$, and $2 \mathrm{~min}$ at $72^{\circ} \mathrm{C}$, and then a final extension was performed at $72^{\circ} \mathrm{C}$ for $7 \mathrm{~min}$. The second PCR conditions were set at $94^{\circ} \mathrm{C}$ for $3 \mathrm{~min}$, followed by 35 cycles of $30 \mathrm{sec}$ at $94^{\circ} \mathrm{C}$, $30 \mathrm{sec}$ at $57^{\circ} \mathrm{C}$, and $2 \mathrm{~min}$ at $72^{\circ} \mathrm{C}$, and then a final extension at $72^{\circ} \mathrm{C}$ for $7 \mathrm{~min}$. The amplification products (171-bp ptsg2 fragment) were cloned into pBluescript II KS(-) vector (Stratagene) and sequenced. 
A 3' portion of medaka ptgs2 was obtained by the 3'-RACE method (Frohman et al., 1988) using the 3'-full RACE Core Set (Takara, Tokyo, Japan) according to the manufacturer's protocol. The sense primers used were COX2S2, COX2S3 and COX2S4 (Table 1). Two rounds of PCR reactions were performed. The first PCR conditions were set at $94^{\circ} \mathrm{C}$ for $3 \mathrm{~min}$, followed by 35 cycles of $1 \mathrm{~min}$ at $94^{\circ} \mathrm{C}, 1 \mathrm{~min}$ at $55^{\circ} \mathrm{C}$, and $2 \mathrm{~min}$ at $72^{\circ} \mathrm{C}$, and then a final extension at $72^{\circ} \mathrm{C}$ for $7 \mathrm{~min}$. The second PCR conditions were set at $94^{\circ} \mathrm{C}$ for $3 \mathrm{~min}$, followed by 35 cycles of $1 \mathrm{~min}$ at $94^{\circ} \mathrm{C}, 1 \mathrm{~min}$ at $58^{\circ} \mathrm{C}$, and $2 \mathrm{~min}$ at $72^{\circ} \mathrm{C}$, and then a final extension at $72^{\circ} \mathrm{C}$ for 7 min. The final PCR products (700-bp ptgs 2 fragment) were subcloned into pBluescript II plasmid for sequencing. The sequencing reaction was performed with the BigDye Terminator Cycle Sequencing Kit v3.1 and analyzed on an ABI PRISM 3100 Genetic Analyzer (Applied Biosystems, Foster City, CA). As a result, a 2,584-bp complete medaka ptgs2 cDNA clone (DDBJ/EMBL/GenBank accession no. $\underline{\mathbf{A B 5 1 6 9 9 3}}$ ) was obtained.

\subsection{Northern blotting}

Northern blot hybridization was performed as described in our previous study (Ogiwara et al., 2004). Briefly, total RNA (60 $\mu$ g for ptgs1a and ptgs $1 b$; $30 \mu \mathrm{g}$ for ptgs2) from various tissues were electrophoretically fractionated on a $1.2 \%$ denaturing agarose gel that contained 2.2 M formaldehyde, transferred to a Nytran-plus membrane (Schleicher and Schuell, Dassel, Germany), and UV cross-linked. cDNA probes for Northern blotting were prepared by PCR using the two specific primers for ptgs1a, ptgs1b, and ptgs2 (Table 1) for the respective cDNA templates. The membranes were separately hybridized with the

${ }^{32}$ P-labeled probes in a buffer containing $50 \%$ formaldehyde, $5 \times 0.15 \mathrm{M} \mathrm{NaCl} / 8.65 \mathrm{mM}$ 
$\mathrm{NaH}_{2} \mathrm{PO}_{4} / 1.25$ mM EDTA (SSPE), $1 \%$ SDS and $5 \times$ Denhardt's solution. The membranes were washed twice in $2 \times$ saline-sodium citrate (SSC) buffer/0.05\% SDS and then in $0.1 \times$ SSC $/ 0.1 \%$ SDS at $50^{\circ} \mathrm{C}$. As a control, medaka cytoplasmic actin (bactin) mRNA was detected with a ${ }^{32}$ P-labeled 312-bp bactin cDNA fragment (Kusakabe et al., 1999). Washed membranes were then subjected to autoradiography.

2.6. Real-time RT-PCR of medaka ovary COX-1a, COX-1b, and COX-2 and PGE receptors

Total RNAs ( $2 \mu \mathrm{g})$ from each sample was reverse-transcribed in a volume of $20 \mu \mathrm{l}$, and the reaction was diluted to $80 \mu \mathrm{l}$ with MilliQ water. The PCR reaction mixture $(10 \mu \mathrm{l})$ contained $1 \times$ SYBR Green PCR Master Mix (Applied Biosystems), $0.1 \mu \mathrm{M}$ of each primer, $0.5 \mu 1$ of sample cDNA or standard cDNA and the PCR was performed using an ABI 7300 Sequence Detector (Applied Biosystems). Reactions were carried out at $50^{\circ} \mathrm{C}$ for 2 min, followed by $95^{\circ} \mathrm{C}$ for $10 \mathrm{~min}$, followed by 40 cycles of $15 \mathrm{sec}$ at $95^{\circ} \mathrm{C}$ and then a final extension for $1 \mathrm{~min}$ at $60^{\circ} \mathrm{C}$. In real-time PCR, the threshold cycle (Ct) is the cycle at which a significant increase in fluorescence takes place. The sequences of the real-time PCR primers for the medaka genes examined are shown in Table 1. Standard cDNAs for quantification were synthesized in vitro using pBluescript II KS(-) vector (Stratagene) constructs containing the respective cDNAs for COX-1a (ptgs1a), COX-1b (ptgs1b), COX-2 (ptgs2), and six $\mathrm{PGE}_{2}$ receptors (EP1a (ptger1a), EP1b (ptger1b), EP2 (ptger2), EP3 (ptger3), EP4a (ptger4a), and EP4b (ptger4b)), cytoplasmic actin (bactin), and 18S rRNA (18S rRNA). The standards were processed in parallel with the cDNA samples and 
were used to generate a standard curve. Dissociation curves were examined after each PCR run to ensure that a single PCR product had been amplified. PCR reactions were performed in triplicate on three separate RNA preparations from independent samples. The sizes of cDNA inserts in the vector were 140 bp (364 to 503, Ensembl gene ID: ENSORLG00000005095 for ptgs1a), 93 bp (1278 to 1370, Ensembl gene ID: ENSORLG00000000509 for ptgs1b), 122 bp (1471 to 1592, DDBJ/EMBL/GenBank accession no. $\underline{\mathbf{A B 5 1 6 9 9 3}}$ for ptgs2), 179 bp (669 to 847, Ensembl gene ID: ENSORLG00000016366 for ptger1a), 105 bp (799 to 903, Ensembl gene ID: ENSORLG00000014518 for ptger1b), 132 bp (797 to 928, Ensembl gene ID: ENSORLG00000003901 for ptger2), 127 bp (797 to 923, Ensembl gene ID: ENSORLG00000007950 for ptger3), 103 bp (1047 to 1149, Ensembl gene ID: ENSORLG00000003780 for ptger4a), 137 bp (957-1093, DDBJ/EMBL/GenBank accession no. $\underline{\mathbf{A B 5 6 3 5 0 4}}$ for ptger4b), 64 bp (654 to 717, DDBJ/EMBL/GenBank accession no. D89627 for bactin), and 56 bp (1415 to 1470, DDBJ/EMBL/GenBank accession no. $\underline{\mathbf{A B 1 0 5 1 6 3}}$ for $18 \mathrm{~S} r R N A)$. The mRNA levels of target genes were normalized to bactin or $18 S$ rRNA mRNA levels.

\subsection{In situ hybridization}

A fragment of ptgs2 cDNA (604 bp), which was the same nucleotide as employed for the Northern blotting, and a fragment of ptger4b cDNA (202 bp), which corresponded to the nucleotide sequence 627-828 (B563504), were used to generate both antisense and sense digoxigenin (DIG)-labeled riboprobes with a DIG RNA Labeling Mix (Roche Diagnostics, Manheim, Germany). The ovaries were isolated from mature medaka at $6 \mathrm{~h}$ 
after ovulation (for ptgs2) or at $3 \mathrm{~h}$ before ovulation (for ptger $4 \mathrm{~b}$ ), frozen, and sectioned at 14- $\mu \mathrm{m}$ thickness. The sections were acetylated and postfixed. Prehybridization, hybridization, and washing of the sections were carried out according to the previously reported protocol (Ogiwara and Takahashi, 2007). The hybridized probes were detected with anti-DIG-alkaline phosphatase (AP) conjugate in a buffer containing nitro blue tetrazolium chloride (NBT) and 5-bromo-4-chloro-3-indolyl phosphate (BCIP) in darkness.

\subsection{COX activity assay}

Tissues were isolated from mature fish at $3 \mathrm{~h}$ before ovulation. Each determination was made using only a single ovary, but using the combined livers or intestines obtained from two fish. After rinsing with phosphate buffered saline (PBS), the tissues were homogenized with $500 \mu \mathrm{l}$ of $100 \mathrm{mM}$ Tris- $\mathrm{HCl}(\mathrm{pH} 7.5)$ and centrifuged at $4^{\circ} \mathrm{C}$ with $10000 \times \mathrm{g}$ for 15 min. The supernatants were used for the enzyme activity assay. For the activity assay of large-sized follicles, the follicles were isolated from mature fish ovaries every $4 \mathrm{~h}$. From a single ovary, 15-20 follicles were obtained at the indicated time point, pooled, homogenized, and centrifuged as described above. The total COX activities of the samples were measured using a COX Activity Assay Kit (Cayman Chemicals) according to the manufacturer's instructions. One unit (U) of the activity was defined as the amount of the enzyme sample that produces $1 \mathrm{nmol}$ of $\mathrm{PGH}_{2}$ per min at $22^{\circ} \mathrm{C}$. The protein concentrations of the samples were determined using a BCA Protein Assay Reagent Kit (Pierce, Rockford, IL). Three determinations were conducted. 


\section{9. $P G E_{2}$ determination}

The tissue levels of $\mathrm{PGE}_{2}$ were determined using a PGE 2 EIA Kit (Assay Designs, Ann Arbor, MI) according to the manufacturer's instructions. Each determination was made using a single ovary, but the combined livers or intestines from three fish. For determination of the ovarian follicle $\mathrm{PGE}_{2}$ level, follicles (6-10 in number) were collected from the ovary of a single fish at each time point, combined, and used. Tissues were homogenized with $500 \mu \mathrm{l}$ of assay buffer containing $1 \mathrm{mM}$ EDTA and $10 \mu \mathrm{M}$ indomethacin and centrifuged at $4^{\circ} \mathrm{C}$ with $10000 \times \mathrm{g}$ for $20 \mathrm{~min}$. The supernatant was measured for the $\mathrm{PGE}_{2}$ level. The protein concentrations of the samples were determined using a BCA Protein Assay Reagent Kit (Pierce). Three determinations (for the ovary, liver and intestine) or five determinations (for the ovarian follicle) were conducted.

\subsection{Statistical analysis}

All the experiments were repeated at least three times, except for the Northern blot analysis, in which two independent experiments were performed. Data are presented as the mean values \pm S.E.M. Differences between groups were evaluated by Student's $t$-test, and the level of statistical significance was set at $\mathrm{P}<0.05$ or $\mathrm{P}<0.01$.

\section{Results}

\subsection{Effects of COX inhibitor on the in vitro ovulation of medaka ovarian follicles}

Large-sized follicles, which were to ovulate in $12 \mathrm{~h}$, were collected from the ovaries and incubated in the absence or presence of inhibitors. At a concentration of $10 \mu \mathrm{M}$ INDO 
(non-selective COX inhibitor), ovulation was strongly inhibited (Fig. 1). Addition of the inhibitor to the medium at $1 \mu \mathrm{M}$ inhibited ovulation by $80 \%$. The concentration of the inhibitor required to inhibit the rate of ovulation by $50 \%$ was calculated to be about $450 \mathrm{nM}$. When dissected follicles were incubated in the presence of both INDO $(10 \mu \mathrm{M})$ and $\mathrm{PGE}_{2}$ $(10 \mu \mathrm{M})$, the inhibitory effect of INDO was completely nullified. These results indicate that COX enzyme(s) and its product $\mathrm{PGE}_{2}$ are involved in the ovulation of the medaka, and that the fish could be a suitable animal model for elucidating the role of PGs in ovulation.

\section{2. cDNA cloning and structure of the medaka ptgs2}

The full-length medaka ptgs2 cDNA was cloned (DDBJ/EMBL/GenBank accession no. AB516993). The cDNA consisted of an 87 bp 5'-untranslated region, an open reading frame of 1824 bp, and a 673 bp 3'-untranslated region. This clone encoded a protein with a predicted length of 607 amino acids (Fig. 2A). A unique domain structure for COX-2 (Simmons et al., 2004) was found in the sequence: a signal peptide (21 residues), epidermal growth factor-like domain/dimerization domain (36 residues), membrane-binding domain (50 residues), catalytic domain (492 residues), and ER retention signal (4 residues) (Fig. 2B).

The catalytic domain of medaka COX-2 contains active site residues (Tyr-374 and Val-512), arachidonic acid binding residues (Arg-109 and Tyr-337), and residues crucial for peroxidase activity (His-377). The protein has four potential N-glycosylation sites (Asn-56, Asn-133, Asn-399, and Asn-584).

We compared our sequence (DDBJ/EMBL/GenBank accession no. $\underline{\text { AB516993) }}$ ) with 
that of medaka COX-2 available from the draft medaka genome sequence database (http://www.ensembl.org/Oryzias_latipes/Info/Index). Amino acid residue substitutions were found at three positions: Ala-167 (our sequence) for Thr (genome database sequence), Thr-401 (our sequence) for Ser (genome database sequence), and Ala-478 (our sequence) for Val (genome database sequence). In addition, our COX-2 protein sequence was two residues shorter than the sequence deduced from the database. An insertion of dipeptide (Gly-Leu), which is missing in our sequence, was present between Gly-20 and Gly-21 in the database sequence of the protein. The current sequence was highly homologous to those of lower vertebrate COX-2 proteins; medaka COX-2 shared $84.6 \%$ identity with killifish COX-2 ( $\underline{\text { AAS21313) }}, 70.2-79.2 \%$ identity with zebrafish COX-2a (

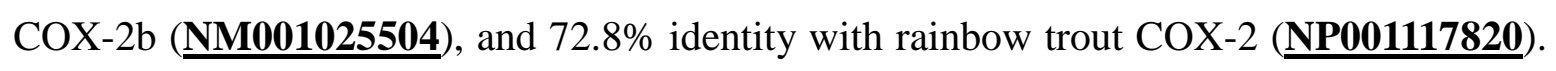
As shown in Fig. 2A, the deduced amino acid sequence of medaka COX-2 is homologous to those of medaka COX-1a (59.5\% identity) or COX-1b (59.4\% identity).

\subsection{Ovarian expression of medaka ptgs $2 \mathrm{mRNA}$}

Northern blot analysis was conducted for ptgs1a, ptgs1b, and ptgs 2 using a blot of total RNA isolated from various tissues (Fig. 3A). The tissue expression patterns of the COX genes were different from each other. They were all expressed in the ovary, although the signals were not very strong. A single band of $3.5 \mathrm{~kb}$ was detected for ptgs2, while two transcript forms were seen for ptgs1a (1.7 and $2.4 \mathrm{~kb})$ and ptgs $1 b$ (1.9 and $2.7 \mathrm{~kb})$. The signal intensities of the ptgs genes relative to the control cytoplasmic actin (bactin) were in the following decreasing order: ptgs $2>$ ptgs1b> ptgs1a (data not shown). We next 
determined the ovarian expression levels of the ptgs $1 a$, ptgs $1 b$, and ptgs 2 genes by real-time PCR analysis. Among the three genes, ptgs2 was found to be expressed most abundantly in the fish ovary (Fig. 3B). The ptgs2 mRNA level was about 20 and 109 times greater than those of ptgs1a and ptgs1b, respectively. Changes in the ptgs 2 expression levels were examined by real-time PCR analysis using the ovaries of mature medaka fish with an established 24 h-spawning cycle. The transcript of ptgs2 was detected throughout the period, and no significant changes in the ptgs2 expression level were seen (Fig. 3C).

\subsection{In situ detection of ptgs 2 mRNA in the ovary of the medaka}

An in situ hybridization analysis of ptgs2 mRNA in the medaka ovary sections was carried out. In ovaries isolated at $6 \mathrm{~h}$ after ovulation, strong signals associated with the oocyte cytoplasm of small-sized growing follicles were detected with the ptgs 2 antisense

probe (Fig. 4A and B). The sizes of ptgs2 mRNA-positive follicles were less than $100 \mu \mathrm{m}$ in diameter. Medium- and large-sized follicles did not show a clear signal. In addition, no clear mRNA expression was seen in the follicular tissue that had ovulated (data not shown). The same morphological result was obtained when ovary sections were prepared at $3 \mathrm{~h}$ before ovulation (data not shown). The results indicate that the oocytes of very small-sized growing follicles contain ptgs 2 mRNA in the cytoplasm at a highly concentrated level.

\subsection{Demonstration of ptgs 2 mRNA expression in the follicle cells}

Having observed that only small-sized follicles exhibited clear positive signals for ptgs2 mRNA in the ovary sections, as described above, we next examined whether or not medium- and large-sized follicles expressed ptgs2 mRNA by real-time PCR. Small-sized 
follicles appeared to contain ptgs 2 mRNA at the highest level, and the transcript level was lowered as the follicles grew (Fig. 5A). We further examined the expression of ptgs2 mRNA using large follicles. The follicle layers and oocytes were isolated from follicles at $-2 \mathrm{~h}$ of ovulation, and their total RNAs were prepared for real-time RT-PCR analysis. As shown in Fig. 5B, the level of ptgs2 mRNA expression was about 3-fold higher in the oocytes than in the layers. Large-sized follicles, which were to ovulate at the next coming ovulation cycle, were analyzed for ptgs 2 mRNA expression every $4 \mathrm{~h}$. The ptgs 2 transcript appeared to be most abundantly present in the follicle isolated at $-7 \mathrm{~h}$ of ovulation, although the difference was not statistically significant. Both the ptgs1a and ptgs $1 b$ expressions in the follicle were very low and could be detected only when RT-PCR was conducted with 35 cycles of amplification (data not shown). These results indicate that the large-sized, preovulatory follicles of the medaka ovary expressed ptgs2 mRNA.

\subsection{COX activity in the medaka ovary}

COX activity was measured using the extracts of the mature fish ovary obtained at $3 \mathrm{~h}$ before ovulation, and the results are shown in Fig. 6, where the activities of the liver and intestinal extracts are included for comparison. Ovarian COX activity was greater than COX activity in the liver, but lower than COX activity in the intestine. This order of enzyme activity levels among the three organs appeared to correspond to that of the ptgs2 mRNA expression levels as examined by Northern blot analysis (Fig. 3A). The enzyme activity was also determined with large-sized ovarian follicles isolated from mature fish every $4 \mathrm{~h}$ (Fig. 6B). COX activity was the highest at $-19 \mathrm{~h}$ and lowest at $-7 \mathrm{~h}$ of ovulation, although such activity changes in the 24-h spawning cycle were not statistically significant. 


\subsection{Ovarian level of $P G E_{2}$}

$\mathrm{PGE}_{2}$ levels were determined for the ovary, liver, and intestine of mature medaka. In the ovary isolated from the fish at $3 \mathrm{~h}$ before ovulation, the PG was reproducibly detected. The amounts of $\mathrm{PGE}_{2}$ were 2920, 218, and $22.0 \mathrm{pg} / \mathrm{mg}$ protein for the intestine, ovary, and liver, respectively (Fig. 7A). Next, the $\mathrm{PGE}_{2}$ levels of large-sized follicles that were destined to ovulate in $24 \mathrm{~h}$ were determined every $4 \mathrm{~h}$. The follicular level of $\mathrm{PGE}_{2}$ was fairly constant throughout this measurement period (Fig. 7B). Follicles isolated at $-15 \mathrm{~h}$ of ovulation seemed to contain the substance at a higher level, but this increase was not statistically significant.

\subsection{Expression of $P G E_{2}$ receptor $m R N A$ in the medaka ovary}

A search of $\mathrm{PGE}_{2}$ receptor genes using the Ensembl website for the medaka genome (http://www.ensembl.org/Oryzias_latipes/Info/Index) revealed that the fish contains six different genes coding for the receptor: ptger1a (for EP1a), ptger1b (for EP1b), ptger2 (for EP2), ptger3 (for EP3), ptger4a (for EP4a), and ptger4b (for EP4b). Using a set of primers synthesized based on the putative transcript sequences for the respective receptors, RT-PCR amplifications were performed. With a fixed 25-cycle reaction using total RNA isolated from the ovary at $3 \mathrm{~h}$ before ovulation, only a PCR product corresponding to ptger $4 b$ was detected (data not shown). Real-time PCR using the same cDNA was conducted to compare the expression levels of EP genes in the ovary. Fixing the ptger1b expression level to 1,

those of ptger1a, ptger2, ptger3, ptger4a, and ptger4b were 1.3, 2.5, 10.4, 9.8, and 141, respectively (Fig. 8A). Next, the expression of ptger4b was examined by real-time RT-PCR 
for large-sized preovulatory follicles of mature medaka ovaries (Fig. 8B). The transcript of ptger $4 b$ was present in the follicle at a very low level during the first half of the 24-h spawning cycle, but its levels were remarkably elevated thereafter, and reached a maximum at $3 \mathrm{~h}$ before ovulation. The relative expression levels of ptger $4 b$ in the follicles were 1 (-23 h), 2.2 (-19 h), 1.8 (-15 h), 47.5 (-11 h), 315 (-7 h), and 431 (-3 h) when the level at $-23 \mathrm{~h}$ was set to 1 . These results indicate that that expression of ptger $4 b$ in the large-sized follicles is increasingly upregulated as the time of ovulation approaches.

\subsection{In situ detection of ptger $4 b$ mRNA in the ovary of the medaka}

In situ detection of ptger $4 b$ mRNA was performed using sections of the fish ovaries isolated $3 \mathrm{~h}$ before ovulation. Clear signals were detected with the antisense probe in the oocyte cytoplasm of small-sized follicles having a diameter greater than $250 \mu \mathrm{m}$ (Fig. 9A and 9B, asterisks). Specific staining was also observed in the follicle layer of the large-sized follicles (Fig. 9B, large arrows). Strong signals associated with small-sized follicles of a diameter less than $80 \mu \mathrm{m}$ were detected (Fig. 9A and 9C, small arrows). However, a comparison with sections treated with the ptger $4 b$ sense probe indicated that these signals are nonspecific.

\subsection{Inhibition of in vitro ovulation by an EP4 antagonist}

Finally, we tested whether the EP4 antagonist GW627368X has an inhibitory effect on the in vitro ovulation of medaka ovarian follicles. A progressive decrease of the rate of ovulation was observed with increasing concentrations of the antagonist (Fig. 10). Under the conditions employed, the $\mathrm{IC}_{50}$ value was calculated to be about $150 \mathrm{nM}$. These results 
indicate that the EP4 receptor may be responsible for exerting the action of $\mathrm{PGE}_{2}$ in the ovulation of the medaka.

\section{Discussion}

A database search indicates that medaka contains two COX-1 genes (ptgs1a and ptgs1b) and one COX-2 gene (ptgs2) (Ishikawa et al., 2007; Havird et al., 2008). However, there has been no scientific report dealing with the cloning and/or expression of any of these medaka COX genes. In the present study, cDNA cloning of medaka ptgs2 was conducted because ptgs 2 was demonstrated to be a dominant COX gene expressed in the mature fish ovary. The putative medaka COX-2 contains a unique set of domain structures found in the mammalian counterparts and possesses conserved amino acid residues essential for its catalytic activity (Simmons et al., 2004). Therefore, medaka COX-2 should serve as a functional enzyme producing $\mathrm{PGH}_{2}$, from which various bioactive PG isomers, such as $\mathrm{PGE}_{2}$ and $\mathrm{PGF}_{2 \alpha}$ are subsequently generated by the actions of isomerases and oxidoreductases (Simmons et al., 2004).

We observed that, compared with the ptgs1a and ptgs $1 b$ mRNA levels, ptgs2 mRNA was always expressed at a dominant level throughout the whole ovary: the ptgs2 mRNA level was approximately 20-fold higher than the ptgs1a mRNA level and 109-fold higher than the ptgs $1 b$ mRNA level. The same was true for the large-sized preovulatory follicles. This dominant expression of ptgs 2 over ptgs1a or ptgs $1 b$ in the medaka ovary is rather distinct from the findings in other teleosts; adult female zebrafish (Grosser et al., 2002; Ishikawa et al., 2007; Lister and Van Der Kraak, 2008) and brook trout (Roberts et al., 
2000) rarely have detectable levels of ptgs 2 in ovarian samples, while cox1 is constitutively expressed. Assuming that active COX proteins are generated in proportion to the amounts of the respective ptgs transcripts, COX-2 could be virtually the only enzyme responsible for PG production in the ovaries of the mature medaka.

In the in situ hybridization analysis of mature medaka ovary sections, clear signals for ptgs2 mRNA expression were detected in the oocytes of small-sized follicles having a diameter of less than $100 \mu \mathrm{m}$. These ptgs2-expressing follicles were at the primary growth/early-previtellogenic stage (stages I and II) of medaka folliculogenesis (Iwamatsu et al., 1988). Localization of ptgs2 transcript in the follicle at this stage suggests that medaka ptgs2 might be involved in follicle development, particularly at the early stages. Such a spatiotemporal expression pattern of medaka ovary ptgs2 resembles that of growth differentiation factor 9 (gdf9) recently reported for zebrafish (Liu and Ge, 2007). In that study, in situ detection of the zebrafish gdf9 transcript showed that the oocytes at the primary growth stage exhibited the strongest staining, and the signals declined progressively with the growth of the follicles.

Because we detected ptgs2 mRNA signals only for small-sized follicles by the morphological analysis of ovary sections, we initially suspected that ptgs2 would not be expressed in the fully-grown follicles of spawning fish. However, real-time RT-PCR analysis revealed that ptgs2 mRNA was expressed in the large follicles. Further analyses revealed that not only oocytes but also follicle cells synthesized ptgs2 mRNA in the large-sized follicles. This finding strongly suggests the involvement of COX-2 in oocyte maturation and/or ovulation of the medaka. This, in turn, raises an intriguing question as to how and to what extent germ cell-expressed COX-2, somatic cell-expressed COX-2, or 
both contribute to these biological processes of the fish. To answer this question, further studies, including the measurement of COX-2 at the protein level and the estimation of catalytic activity for the enzyme localized in the two different cell types, are necessary. At any rate, a plausible explanation for our failure to demonstrate ptgs2 mRNA expression in the medium- and large-sized follicles by in situ hybridization experiments is that only small-sized follicles express the ptgs2 transcript in quantities sufficient to produce clear signals.

Previous studies using mammalian species have established that ptgs2 is inducible (Espey and Richards, 2006). Evidence for the inducible nature of ptgs2 has also been reported for zebrafish (Grosser et al., 2002; Ishikawa et al., 2007; Lister and Van Der Kraak, 2009), rainbow trout (Zou et al., 1999; Ishikawa and Herschman, 2007), and brook trout (Roberts et al., 2000). However, in the present study the ptgs2 transcript levels were fairly constant in the ovary as well as in the large-sized follicles of mature medaka during the 24-h spawning cycle. These observations would seem to argue against the notion that medaka ptgs2 is an inducible gene. We should note that many immediate-early genes often contain the AUUUA Shaw-Kamen motif (Shaw and Kamen, 1985), a pentameric sequence, in the AU-rich elements (AREs) of the 3'-untranslated region (UTR) of the mRNA (Dean et al., 2004; Espel, 2005). Indeed, multiple AREs motifs are present in common in the extended 3' UTR of zebrafish, rainbow trout, and brook trout ptgs2 mRNA (Roberts et al., 2000). Interestingly, seven AUUUA Shaw-Kamen motifs were also found in the 3' UTR of medaka ptgs2 mRNA. Obviously, medaka ovary ptgs2 expression is presumed to be regulated in a manner distinct from the ovary ptgs2 expression of the other three teleosts.

We detected COX activity in the extract of the fish ovary. In our in vitro ovulation 
experiments using large-sized ovarian follicles, we found that ovulation was effectively suppressed by the COX inhibitor indomethacin, and that this suppression was prevented by concomitant addition of $\mathrm{PGE}_{2}$. These findings strongly suggest that intra-follicular generation of $\mathrm{PGE}_{2}$ is essential for successful ovulation of the fish. As discussed above, we conclude that COX-2 may be responsible for the production of $\mathrm{PGE}_{2}$ in the large-sized follicles.

In contrast to the previous observation that PGs were produced at the time of ovulation in the brook trout ovary (Goetz and Cetta, 1983; Goetz and Garczynski, 1997), in the present study $\mathrm{PGE}_{2}$ was always detectable in the large-sized follicles of the medaka and its levels did not change significantly during the 24-h spawning cycle. Since $\mathrm{PGE}_{2}$ is synthesized by a series of enzymatic reactions involving phospholipase $A_{2}, C O X$, and PGE synthase, the quantity of the metabolite is undoubtedly the result of the concerted actions of these enzymes. Insights into the mechanisms by which the $\mathrm{PGE}_{2}$ levels in the large-sized follicles are determined await further investigations. In the present work, inclusion of indomethacin in the culture medium of the in vitro follicle ovulation experiments during the last $12 \mathrm{~h}$ prior to ovulation effectively suppressed the release of oocytes. This observation strongly suggests that exposure to $\mathrm{PGE}_{2}$ at this time point is critical for the fully grown follicles to ovulate.

In order for $\mathrm{PGE}_{2}$ to exert such an effect, the target cells must have specific receptors (EP) on the cell surface (Sugimoto and Narumiya, 2007). In this study, we demonstrated the dominant expression of the ptger $4 b$ gene in the fish ovary. In addition, the expression of ptger $4 b$ was dramatically increased in the large-sized follicles, which are destined to ovulate as the time of ovulation approaches. More importantly, the EP4 antagonist 
(GW627368X) drastically reduced the rate of in vitro ovulation. These facts tempt us to speculate that EP4b may be the receptor responsible for mediating the actions of $\mathrm{PGE}_{2}$ and that its expression on the surface of target cells may be critical for exerting an ovulation-inducing effect of the prostanoid in the medaka ovarian follicles. As clearly shown by our in situ hybridization analysis, ptger $4 b$ mRNA was localized in the follicle layer of the ovulating large-sized follicles. Transcripts of ptgs2 were also demonstrated to be present in the same layer of the large-sized follicles. Therefore, the translated products of both COX-2 and EP4b should be associated with the follicle layer cells (granulosa cells or theca cells) of ovulating follicles. Identification of cells expressing COX-2 and/or EP4b in the follicle will be important for understanding how $\mathrm{PGE}_{2}$ is involved in the fish ovulation.

In summary, the present study reports for the first time the expression of PGE $_{2}$-producing enzyme COX-2 (ptgs2) and PGE2 receptor EP4b (ptger4b) mRNA in the medaka ovary. The current results strongly suggest the involvement of COX-2/EP4b in the ovulatory process of the fish. This study has established the basis for further investigations to define the mechanism of the role of $\mathrm{PGE}_{2}$ in the ovulation of the medaka.

\section{Acknowledgments}

This study was supported by Grants-in-Aid for Scientific Research from the Ministry of Education, Culture, Sports, Science, and Technology of Japan (19657021 and 21370024 to T.T).

\section{References}


Armstrong, D.T., 1981. Prostaglandins and follicular functions. J Reprod. Fertil. 62, 283-291.

Cetta, F., Goetz, F.W., 1982. Ovarian and plasma prostaglandin E and F levels in brook trout (Salvelinus fontinalis) during pituitary-induced ovulation. Biol. Reprod. 27, 1216-1221.

Cha, Y.I., Kim, S.H., Sepich, D., Buchanan, F.G., Solnica-Krezel, L., DuBois, R.N., 2006. Cyclooxygenase-1-derived PGE 2 promotes cell motility via the G-protein-coupled EP4 receptor during vertebrate gastrulation. Genes Dev. 20, 77-86.

Chang, K.J., Kim, J.W., Im, W.B., Kang, H.M., Kwon, H.B., 1997. Differential effects of gonagotropin and orthovanadate on oocyte maturation, ovulation, and prostaglandin synthesis by Rana ovarian follicles in vitro. J. Exp. Zool. 277, 155-165.

Chang, K.J., Kim, J.W., Lee, J., Im, W.B., Kwon, H.B., Scheutz, A.W., 1995. Prostaglandin production and ovulation during exposure of amphibian ovarian follicles to gonadotropin or phorbol ester in vitro. Gen. Comp. Endocrinol. 100, 257-266.

Dean, J.L.E., Sully, G., Clark, A.R., Saklatvala, J.. 2004. The involvement of AU-rich element-binding proteins in p38 mitogen-activated protein kinase pathway-mediated mRNA stabilization. Cell Signal. 16, 1113-1121.

Espel, E., 2005. The role of the AU-rich elements of mRNAs in controlling translation. Semin. Cell. Dev. Biol. 16, 59-67.

Espey, L.L., 1994. Current status of the hypothesis that mammalian ovulation is compatible to an inflammatory reaction. Biol, Reprod. 50, 233-238.

Espey, L.L., Richards, J.S., 2006. Ovulation. In: Neill, J.D. (eds.), Physiology of reproduction. Academic Press, Amsterdam, vol 1, 3rd edition, pp. 425-474. 
Frohman, M.A., Dush, M.K., Martin, G.R., 1988. Rapid production of full-length cDNA from rare transcripts: amplification using a sigle gene-specific oligonucleotide primer. Proc. Natl. Acad. Sci. U.S.A .85, 8998-9002.

Goetz, F.W., Cetta, F., 1983. Ovarian and plasma PGE and PGF levels in naturally ovulating brook trout (Salvelinus fontinalis) and the effects of indomethacin on prostaglandin levels. Prostaglandins 26, 387-395.

Goetz, F.W., Garczynski, M., 1997. The ovarian regulation of ovulation in teleost fish. Fish Physiol. Biochem. 17, 33-38.

Goetz, F.W., Nagahama, Y., 1985. The in vitro effects of cyclic nucleotides on prostaglandin-induced ovulation of goldfish (Carassius auratus). Zool. Sci. 2, 225-228.

Goetz, F.W., Theofan, G., 1979. In vitro stimulation of germinal vesicle breakdown and ovulation of yellow perch (Perca flavescens) oocytes. Effects of 17 alpha-hydroxyl-20 beta-dihydroprogesterone and prostaglandins. Gen. Comp. Endocrinol. 37, 273-285.

Grosser, T., Yusuff, S., Cheskis, E., Pack, M., FitzGerald, G., 2002. Developmental expression of functional cyclooxygenases in zebrafish. Proc. Natl. Acad. Sci. U.S.A. 99, 8418-8423.

Hata, A.N., Breyer, R.M., 2004. Pharmacology and signaling of prostaglandin receptors: multiple roles in inflammation and immune modulation. Pharmacol Ther. 103, 147-66.

Havird, J.C., Miyamoto, M.M., Choe, K.P., Evans, D,H., 2008. Gene duplications and losses within the cyclooxygenase family of teleosts and other chordates. Mol. Biol. Evol. 25, 2349-2359.

Hizaki, H., Segi, E., Sugimoto, Y., Hirose, M., Saji, T., Ushikubi, F., Matsuoka, T., Noda, Y., Tanaka, T., Yoshida, N., Narumiya, S., Ichikawa, A., 1999. Abortive expansion of the 
cumulus and impaired fertility in mice lacking the prostaglandin $\mathrm{E}$ receptor subtype $\mathrm{EP}_{2}$. Proc. Natl. Acad. Sci. U.S.A. 96, 10501-10506.

Ishikawa, Y., 2000. Medakafish as a model system for vertebrate developmental genetics. BioEsseys 22, 487-495.

Ishikawa, T., Griffin, K.J.P., Banerjec, U., Herschman, H.R., 2007. The zebrafish genome contains two inducible, functional cyclooxygenase-2 genes. Biochem. Biophys. Res. Commun. 352, 181-187.

Ishikawa, T., Herschman, H.R., 2007. Two inducible, functional cyclooxygenase-2 genes are present in the rainbow trout genome. J. Cell. Biochem. 102, 1486-1492.

Iwamatsu, T., 1978. Studies on oocyte maturation of the medaka, Oryzias latipes. VI. Relationship between the circadian cycle of oocyte maturation and activity of the pituitary gland. J. Exp. Zool. 206, 355-364.

Iwamatsu, T., Ohta, T., 1989. Effects of forskolin on fine structure of medaka follicles. Dev. Growth Differ. 31, 45-53.

Iwamatsu, T., Ohta, T., Oshima, E., Sakai, N., 1988. Oogenesis in the medaka Oryzias latipes. Stage of oocyte development. Zool. Sci. 5, 353-373.

Jalabert, B, Szölösi, D., 1975. In vitro ovulation of trout oocytes: Effects of prostaglandins on smooth muscle-like cells of the theca. Prostaglandins 9, 765-778.

Järving, R., Järving, I., Kurg, R., Brash, A.R., Samel, N., 2004. On the evolutionary origin of cyclooxygenase (COX) isozymes. J. Biol. Chem. 279, 13624-13633.

Kagawa, H., Nagahama, Y., 1981. In vitro effects of prostaglandins on ovulation in goldfish, Carassuys auratus. Bull. Jpn. Soc. Sci. Fish. 47, 1119-1121.

Kagawa, H., Tanaka, H., Unuma ,T., Ohta, H., Gen, K., Kuzawa, K., 2003. Role of 
prostaglandin in the control of ovulation in the Japanese eel Anguilla japonica. Fisheries Sci. 69, 234-241.

Kasahara, M., Naruse, K., Sasaki, S., et al. 2007. The medaka draft genome and insights into vertebrate genome evolution. Nature 447, 714-719.

Kusakabe, R., Kusakabe, T., Suzuki, N., 1999. In vivo analysis of two striated muscle actin promoters reveals combinations of multiple regulatory modules required for skeletal and cardiac muscle-specific gene expression. Int. J. Dev. Biol. 43, 541-554.

LeMaire, W.J., Leidner, R., Marsh, J.M., 1975. Pre and post ovulatory changes in the concentration of prostaglandins in rat graafian follicles. Prostaglandins 9, 221-229.

LeMaire, W.J., Yang, N.S., Behrman, H.H., Marsh, J.M., 1973. Preovulatory changes in the concentration of prostaglandins in rabbit graafian follicles. Prostaglandins 3, 367-376.

Lister, A.L., Van Der Kraak, G., 2008. An investigation into the role of prostaglandins in zebrafish oocyte maturation and ovulation. Gen. Comp. Endocrinol. 159, 46-57.

Lister, A.L., Van Der Kraak, G., 2009.Regulation of prostaglandin synthesis in ovaries of sexually-mature zebrafish (Danio rerio). Mol. Reprod. Dev. 76, 1064-1075.

Liu, L., Ge, W., 2007. Growth differentiation factor 9 and its spatiotemporal expression and regulation in the zebrafish ovary. Biol. Reprod. 76, 294-302.

Murdoch W.J., Hansen, T.R., McPherson, L.A., 1993. A review-Role of eichosanoids in vertebrate ovulation. Prostaglandins, 46, 85-115.

Nagahama, Y., 1994. Endocrine regulation of gametogenesis in fish. Int. J. Dev. Biol. 38, 217-229.

Nagahama, Y., Yoshikuni, M., Yamashita, M., Tanaka, M., 1994. Regulation of oocyte maturation in fish. In: Sherwood, N.M., Hew, C.L. (eds.), Fish Physiology. Academic 
Press, New York, pp. 393-439.

Ogiwara, K., Shinohara, M., Takahashi, T., 2004. Expression of proprotein convertase 2 mRNA in the ovarian follicles of the medaka, Oryzias latipes. Gene 337, 79-89.

Ogiwara, K., Takahashi, T., 2007. Specificity of the medaka enteropeptidase serine protease and its usefulness as a biotechnological tool for fusion-protein cleavage. Proc. Natl. Acad. Sci. U.S.A. 104, 7021-7026.

Ogiwara, K., Takano, N., Shinohara, M., Murakami, M., Takahashi, T., 2005. Gelatinase A and membrane-type matrix metalloproteinases 1 and 2 are responsible for follicle rupture during ovulation in the medaka. Proc. Natl. Acad. Sci. U.S.A. 102, 8442-8447.

Orczyk, G. P., Berhman, H. R., 1972. Ovulation blockade by aspirin or indomethacin - in vivo evidence for a role of prostaglandin in gonadotrophin secretion. Prostaglandins. 1, 3-20.

Ozato, K., Wakamatsu, Y., 1994. Developmental genetics of medaka. Dev. Growth Differ. 36, 437-443.

Pankhurst, N.W., 1985. Final maturation and ovulation of oocytes of the goldeye, Hiodon alasoides (Rahubesque), in vitro. Can. J. Zool. 63, 1003-1009.

Patino, R., Yoshizaki, G., Bolamba ,D., Thomas, P., 2003. Role of arachidonic acid and protein kinase $\mathrm{C}$ during maturation-inducing hormone-dependent meiotic resumption and ovulation in ovarian follicles of Atlantic croaker. Biol. Reprod. 68, 516-523.

Pendergrass, P.C., Schroeder, P., 1976. The ultrastructure of the thecal cell of the teleost, Oryzias latipes, during ovulation in vitro. J. Reprod. Fertil. 47, 229-233.

Ramos, I., Cisint, S.B., Crespo, C.A., Medina, M.F., Fernandez, S.N., 2008. Modulators of Bufo arenarum ovulation. Zygote 16, 65-72. 
Richards, J.S., Russell, D.L., Ochsner, S., Espey, L.L., 2002. Ovulation: new dimensions and new regulators of the inflammatory-like response. Annu. Rev. Physiol. 64, 69-92.

Roberts, S.B., Langenau, D.M., Goetz, F.W., 2000. Cloning and characterization of prostaglandin endoperoxide synthase-1 and -2 from the brook trout ovary. Mol. Cell. Endocrinol. 160, 89-97.

Schuetz, A.W., 1986. Hormonal dissociation of ovulation and maturation of oocytes: ovulation of immatureamphibian oocytes by prostaglandin. Gamete Res. 15, 99-113.

Sena, J., Liu, Z., 2008. Expression of cyclooxygenase genes and production of prostaglandins during ovulation in the ovarian follicles of Xenopus laevis. Gen. Comp. Endocrinol. 157, 165-173.

Shaw, G., Kamen, R., 1985. A conserved AU sequence from the 3' untranslated region of GM-CSF mRNA mediates selective mRNA degradation. Cell 46:659-667.

Simmons, D.L., Botting, R.M., Timothy, H., 2004. Cyclooxygenase isozymes: The biology of prostaglandin synthesis and inhibition. Pharmacol. Rev. 56, 387-437.

Stacey, N.E., Pandey, S., 1975. Effects of indomethacin and prostaglandins on ovulation of goldfish. Prostaglandins 9, 597-607.

Sugimoto, Y., Narumiya, S., 2007. Prostaglandin E receptors. J. Biol. Chem. 282, 11613-11617.

Villablanca, E.J., Pistocchi, A., Court, F.A., Cotelli, F., Bordignon, C., Allende, M.L., Traversari, C., Russo, V., 2007. Abrogation of prostaglandin E2/EP4 signaling impairs the development of rag1+ lymphoid precursors in the thymus of zebrafish embryos. J. Immunol. 179, 357-64.

Wittbrodt, J., Shima, A., Schartl, M., 2002. Medaka--a model organism from the far East. 
Nat. Rev. Genet. 3, 53-64.

Zou, J., Neumann, N.F., Holland, J.W., Belosevic, M., Cunningham, C., Secombes, C.J., Rowley, A.F., 1999. Fish macrophage express a cyclo-oxygenase-2 homologue after activation. Biochem. J. 340, 153-159. 


\section{FIGURE LEGENDS}

Fig. 1. Effect of COX inhibitor on in vitro ovulation in the medaka ovarian follicles.

Large-sized follicles (at least 10 follicles/experiment) isolated from mature fish ovaries were incubated with a non-selective COX inhibitor indomethacin (INDO) at concentrations ranging from 0.01 to $10 \mu \mathrm{M}$. In some experiments, the follicles were incubated in the medium containing both INDO $(10 \mu \mathrm{M})$ and $\mathrm{PGE}_{2}(10 \mu \mathrm{M})$. In parallel experiments, follicles were incubated in medium containing ethanol alone as a control. The ovulation rates were determined at $6 \mathrm{~h}$ after ovulation. The results are shown as the mean \pm S.E.M. $(\mathrm{n}=3)$. Asterisks indicate significant differences at $\mathrm{P}<0.01(*)$ as compared to the control.

Fig. 2. Deduced amino acid sequence of medaka COX-2 and its domain structure.

(A) The primary sequence of medaka COX-2 (the present study) is compared with those of medaka COX-1a (Ensembl gene ID: ENSORLG00000005095) and COX-1b (Ensembl gene ID: ENSORLG00000000509). The putative signal peptide cleavage site is indicated by an arrowhead. Identical residues in the three COX proteins are boxed and shaded in gray. The residues (Tyr-374 and Val-512) of the Cox active site are indicated by asterisks. The residues essential for peroxidase activity (His-377) and for binding arachidonic acid (Arg-109 and Tyr-337) are indicated by filled circles and open circles, respectively. The asparagine residues (Asn-56, Asn-133, Asn-399, and Asn-584) for putative $N$-glycosylation are indicated by triangles. (B) The domain structure of medaka COX-2 is shown. SP, signal peptide; EGF, epidermal growth factor-like domain/dimerization domain; MBD, membrane-binding domain; and ER, ER retention signal. The numbers of amino acid residues in each domain are indicated at the bottom of 
the figure.

Fig. 3. Expression of ptgs2 mRNA in the medaka ovary.

(A) Northern blot analyses were conducted using a membrane loaded with $60 \mu \mathrm{g}$ (for ptgs1a and ptgs $1 b$ ) or $30 \mu \mathrm{g}$ (for ptgs2) of total RNA isolated from various tissues of the mature medaka fish. The membranes were separately hybridized with ${ }^{32} \mathrm{P}$-labeled cDNA fragments of ptgs genes. The lower panel of each set shows the detection of medaka cytoplasmic actin (bactin) mRNA with the ${ }^{32} \mathrm{P}$-labeled bactin cDNA fragment. The results of one representative experiment out of two independent experiments with similar findings are presented. (B) Real-time RT-PCR analysis was conducted for ptgs1a, ptgs1b, and ptgs2 using total RNA isolated from the mature medaka ovary. Data are presented as the mean \pm S.E.M. (n=3). (C) Real-time RT-PCR analysis was performed for ptgs2 using total RNA isolated from the ovaries of mature medaka with a 24 h-cycle of spawning. The expression levels were normalized to that of bactin and expressed as the fold change of the levels of the -23 h ovary. Data are presented as the mean \pm S.E.M. $(n=3)$.

Fig. 4. In situ detection of ptgs2 mRNA in the medaka ovary.

Medaka ovaries isolated at $6 \mathrm{~h}$ after ovulation were used. Neighboring sections of the ovaries were hybridized with DIG-labeled ptgs2 antisense (A and B) or sense (C and D) RNA probes. The boxed areas in (A) and (C) are shown at higher magnification in (B) and (D), respectively. Positively stained oocytes of small-sized growing follicles are indicated by an arrow. \#, medium-sized follicles; +, large-sized follicles that are destined to ovulate at 
the next cycle of ovulation. The scale bars represent $500 \mu \mathrm{m}$ (A and C) and $200 \mu \mathrm{m}$ (B and D). The reproducibility of the findings was confirmed by conducting three independent experiments, and the results of a representative experiment are presented.

Fig. 5. Expression of ptgs2 mRNA in the ovarian follicles.

(A) Real-time RT-PCR analysis of ptgs2 mRNA using different sizes of ovarian follicles. Total RNA was isolated from small-, medium- and large-sized follicles of the fish ovaries at $3 \mathrm{~h}$ before ovulation. The expression levels of the ptgs 2 mRNA were normalized with those of the medaka cytoplasmic actin (bactin) transcript that was measured on the same cDNAs. The results are presented as the mean \pm S.E.M. $(n=3)$, and the mRNA levels are shown relative to that of large-sized follicles. (B) Real-time RT-PCR analysis of ptgs2 mRNA using oocytes and follicle layers of ovarian follicles. Oocytes and follicle layers were prepared from large-sized ovarian follicles isolated from mature medaka at $2 \mathrm{~h}$ before ovulation, and the total RNAs were separately prepared. The expression levels of the ptgs2 mRNA were normalized with medaka bactin, and expressed as the fold change of the levels of the follicle layer. The results are presented as the mean \pm S.E.M. $(n=3)$. (C) Real-time RT-PCR analysis of ptgs2 mRNA using large-sized follicles. The large-sized follicles, which were destined to ovulate in $24 \mathrm{~h}$, were isolated from the fish ovaries at the indicated time points. The expression levels were normalized to that of bactin and expressed as the fold change of the levels of the $-23 \mathrm{~h}$ follicle. Data are presented as the mean values \pm S.E.M. $(n=3)$. 
Fig. 6. COX activity in the mature medaka ovary.

(A) Ovaries, livers and intestines were obtained from the mature female medaka at $3 \mathrm{~h}$ before ovulation. (B) Large-sized follicles were isolated from mature fish ovaries at the indicated time points. Enzyme samples were prepared as described in the Materials and methods. COX activity assays were conducted according to the manufacturer's protocol using tissue and follicle extracts containing approximately $30 \mu \mathrm{g}$ protein/reaction. The results are shown as the mean \pm S.E.M. $(\mathrm{n}=3)$.

Fig. 7. $\mathrm{PGE}_{2}$ levels in the medaka ovary.

(A) Ovaries, livers and intestines were obtained from mature female medaka at $3 \mathrm{~h}$ before ovulation, and used for $\mathrm{PGE}_{2}$ determination. $\mathrm{PGE}_{2}$ were determined according to the manufacturer's protocol using the extracts. The results are shown as the mean \pm S.E.M. $(n=3)$. (B) Large-sized follicles were isolated from mature female medaka ovaries every $4 \mathrm{~h}$, and were used for $\mathrm{PGE}_{2}$ determination. The results are shown as the mean \pm S.E.M. (n=5).

Fig. 8. Expression of $\mathrm{PGE}_{2}$ receptor mRNA in the medaka ovary.

(A) Real-time RT-PCR analysis of ptger mRNA using total RNA isolated from the ovaries of mature fish at $3 \mathrm{~h}$ before ovulation. The expression levels of the ptger mRNA were normalized with medaka bactin and expressed as the fold change of the levels of the ptger1a. The results are shown as the mean \pm S.E.M. $(\mathrm{n}=3)$. (B) Real-time RT-PCR analysis of ptger $4 b$ mRNA using large-sized follicles. The large-sized follicles, which were destined to ovulate in $24 \mathrm{~h}$, were isolated from the fish ovaries at the indicated time points. The expression levels of ptger $4 b$ mRNA were normalized to that of bactin and expressed as the 
fold change of the levels of the $-23 \mathrm{~h}$ follicle. Data are presented as the mean values \pm S.E.M. $(\mathrm{n}=3)$.

Fig. 9. In situ detection of ptger $4 b$ mRNA in the medaka ovary.

Medaka ovaries isolated at $3 \mathrm{~h}$ before ovulation were used. Neighboring sections of the ovaries were hybridized with DIG-labeled ptger4b antisense (A and B) or sense (C and D) RNA probes. The boxed areas in (A) and (C) are shown at higher magnification in (B) and (D), respectively. Positively stained oocytes of small-sized growing follicles are indicated by an asterisk. Positive staining associated with the follicle layers of large-sized follicles are indicated by a large arrow. Small arrows indicate non-specific staining associated with small-sized follicles with a diameter less than $80 \mu \mathrm{m}$. +, large-sized follicles that are destined to ovulate at the next cycle of ovulation. The scale bars represent $500 \mu \mathrm{m}$ (A and C) and $200 \mu \mathrm{m}(\mathrm{B}$ and $\mathrm{D})$. The reproducibility of the findings was confirmed by conducting three independent experiments, and the results of a representative experiment are presented.

Fig. 10. Effect of EP4 antagonist on in vitro ovulation in the medaka ovarian follicles.

Large-sized follicles (at least 10 follicles/experiment) isolated from mature fish ovaries were incubated with GW627368X (EP4 antagonist) at concentrations ranging from 0.01 to $10 \mu \mathrm{M}$. In parallel experiments, follicles were incubated in medium containing DMSO alone as a control. The ovulation rates were determined at $6 \mathrm{~h}$ after ovulation. The results are shown as the mean \pm S.E.M. $(\mathrm{n}=3)$. Asterisks indicate significant differences at $\mathrm{P}<0.01$ $(*)$ as compared to the control. 
Table 1. Primers used for cloning, Northern blotting, in situ hybridization, and real-time PCR.

\begin{tabular}{llll}
\hline Primer name & Gene & Primer sequence & Accession No. \\
\hline Cloning / 3'-RACE / 5'-RACE & & AB516993 \\
\hline COX2S1 & ptgs2 & 5'-ATGAACTCACTTAGAGCTGTG -3' & \\
COX2S2 & ptgs2 & 5'-GCTCGTTTGTGACAATGTCAG-3' & \\
COX2S3 & ptgs2 & 5'-CTCTCGCCTAGCAGATGTCAA-3' & \\
COX2S4 & ptgs2 & 5'-CTGAAGGAAAGGACTACTGAA-3' & \\
COX2AS1 & ptgs2 & 5'-TCAGGTTTTACCTCTCCCA-3' & \\
COX2AS2 & ptgs2 & 5'-CCCAAACTTGTGCACAC-3' & \\
COX2AS3 & ptgs2 & 5'-GCACACACCTCTGTTCTGGCAAGG-3' & \\
COX2AS4 & ptgs2 & 5'-AGGCCATGAGCAGCACGGATTAC-3' & \\
Northern blotting / in situ hybridization & & \\
COX2S4 & ptgs2 & 5'-CTGAAGGAAAGGACTACTGAA-3' & AB516993 \\
COX2AS1 & ptgs2 & 5'-TCAGGTTTTACCTCTCCCA-3' & \\
COX1aS1 & ptgs1a & 5'-GGCTACCTCAACTGGGAATC-3' & ENSORLG00000005095 \\
COX1aAS1 & ptgs1a & 5'-CAGACCCAAACCTGGTAGGAG-3' & \\
COX1bS1 & ptgs1b & 5'-GGAGAAACTGGTGGATGCTT-3' & ENSORLG00000000509 \\
COX1bAS1 & ptgs1b & 5'-TCCTGCCTCTTCCTGGTTTGG-3' & \\
EP4bSS1 & ptger4b & 5'-GCAGCGCTCTCTCTTCTTGG-3' & AB563504 \\
EP4bAS1 & ptger4b & 5'-TGCAGATGACCG-3' & \\
RT-PCR & & 5'-TTCTGCTTCCAGGGGGACCCA-3' & \\
EP1aSS1 & ptger1a & 5'-AGATCCGTGGCTTTGGTGCCA-3' & \\
EP1aAS1 & ptger1a & 5'-TTACCAAACCGCTGCCACATA-3' & \\
EP1bSS1 & ptger1b & & \\
\hline
\end{tabular}


Table 1. (continued)

\begin{tabular}{|c|c|c|c|}
\hline Primer name & Gene & Primer sequence & Accession No. \\
\hline EP1bAS1 & ptger $1 b$ & 5’-CAGCTTCAGTACGCTGACTGT-3’ & \\
\hline EP2SS1 & ptger2 & 5’-GCTGCAGGCATCTTCGGCAAC-3’ & ENSORLG00000003901 \\
\hline EP2AS1 & ptger2 & 5’-CGATCGGTTTGCTCACAGTGA-3’ & \\
\hline EP3SS1 & ptger3 & 5’-GACAGCAAAGTGCCAGGAAAC-3’ & ENSORLG00000007950 \\
\hline EP3AS1 & ptger3 & 5’-CAGAGTCCTGCTGTTATTAGC-3’ & \\
\hline EP4aSS1 & ptger4a & 5’-AGTTGGCCGGATTCACTCTG-3’ & ENSORLG00000003780 \\
\hline EP4aAS1 & ptger4a & 5’-GACATCCTGCGCACAAAGCG-3’ & \\
\hline EP4bSS1 & ptger $4 b$ & 5’-GCAGCGCTCTCTCTTCTTGG-3’ & AB563504 \\
\hline EP4bAS2 & ptger $4 b$ & 5’-GGTCTTCATTGATCAGTGAGG-3’ & \\
\hline OLCA1SS & bactin & 5’-CAGACACGTATTTGCCTCTG-3’ & D89627 \\
\hline OLCA1AS & bactin & 5’-CAAGTCGGAACACATGTGCA-3’ & \\
\hline \multicolumn{4}{|c|}{ Real-time RT-PCR } \\
\hline COX2S5 & ptgs 2 & 5'-AAGCCCTATGCGTCTTTTGA-3’ & AB516993 \\
\hline COX2AS5 & ptgs2 & 5’-CGGGGTTTCTCAACCAGTAG-3’ & \\
\hline COX1aS1 & ptgs1a & 5’-GGCTACCTCAACTGGGAATC-3’ & ENSORLG00000005095 \\
\hline COX1aAS2 & ptgs1a & 5’-AGССТСТССАССАСААССТ-3’ & \\
\hline COX1bS1 & ptgs1b & 5’-GGAGAAACTGGTGGATGCTT-3’ & ENSORLG00000000509 \\
\hline COX1bAS2 & ptgs $1 b$ & 5’-ATCTGGGCCACCTTAAGAAC-3’' & \\
\hline EP1aSS2 & ptger1a & 5’-CGTAAGGTCCCACGATACAG-3’ & ENSORLG00000016366 \\
\hline EP1aAS2 & ptger1a & 5’-TTCTGACGCCGGTCACCATC-3’ & \\
\hline EP1bSS2 & ptger $1 b$ & 5'-ACGGTCACCTCCTGCATC-3' & ENSORLG00000014518 \\
\hline EP1bAS2 & ptger $1 b$ & 5’-TTTGTAGCTGCACAGCTTGTC-3’ & \\
\hline
\end{tabular}


Table 1. (continued)

\begin{tabular}{|c|c|c|c|}
\hline Primer name & Gene & Primer sequence & Accession No. \\
\hline EP2SS2 & ptger2 & 5’-AGGAGGTGGAGCATCTCATC-3' & ENSORLG00000003901 \\
\hline EP2AS2 & ptger2 & 5’-CCGTCAGATCCAAAATGTGA-3’ & \\
\hline EP3SS2 & ptger3 & 5’-CTCCTCTGCTGGTACTGATG-3’ & ENSORLG00000007950 \\
\hline EP3AS2 & ptger3 & 5’-AGACGAATCGCTGTCAGAAA-3' & \\
\hline EP4aSS2 & ptger4a & 5’-GCAAGATGCCACAAACACTT-3’ & ENSORLG00000003780 \\
\hline EP4aAS2 & ptger4a & 5’-GAGTGCGGGATCTTTTGAAT-3’ & \\
\hline EP4bSS2 & ptger $4 b$ & 5’-CAGATGGTGATCCTGCTCAT-3’ & AB563504 \\
\hline EP4bAS3 & ptger $4 b$ & 5’-GCCAGGAGGTCTTCATTGAT-3’ & \\
\hline OLCA1S2 & bactin & 5’-TGACGGAGCGTGGCTACTC-3’ & D89627 \\
\hline OLCA1AS2 & bactin & 5’-TCCTTGATGTCACGGACAATTT-3’ & \\
\hline 18SS1 & $18 S$ rRNA & 5’- CGTTCAGCCACACGAGATTG-3’' & AB105163 \\
\hline 18SAS1 & $18 S$ rRNA & 5’-CCGGACATCTAAGGGCATCA -3’ & \\
\hline
\end{tabular}




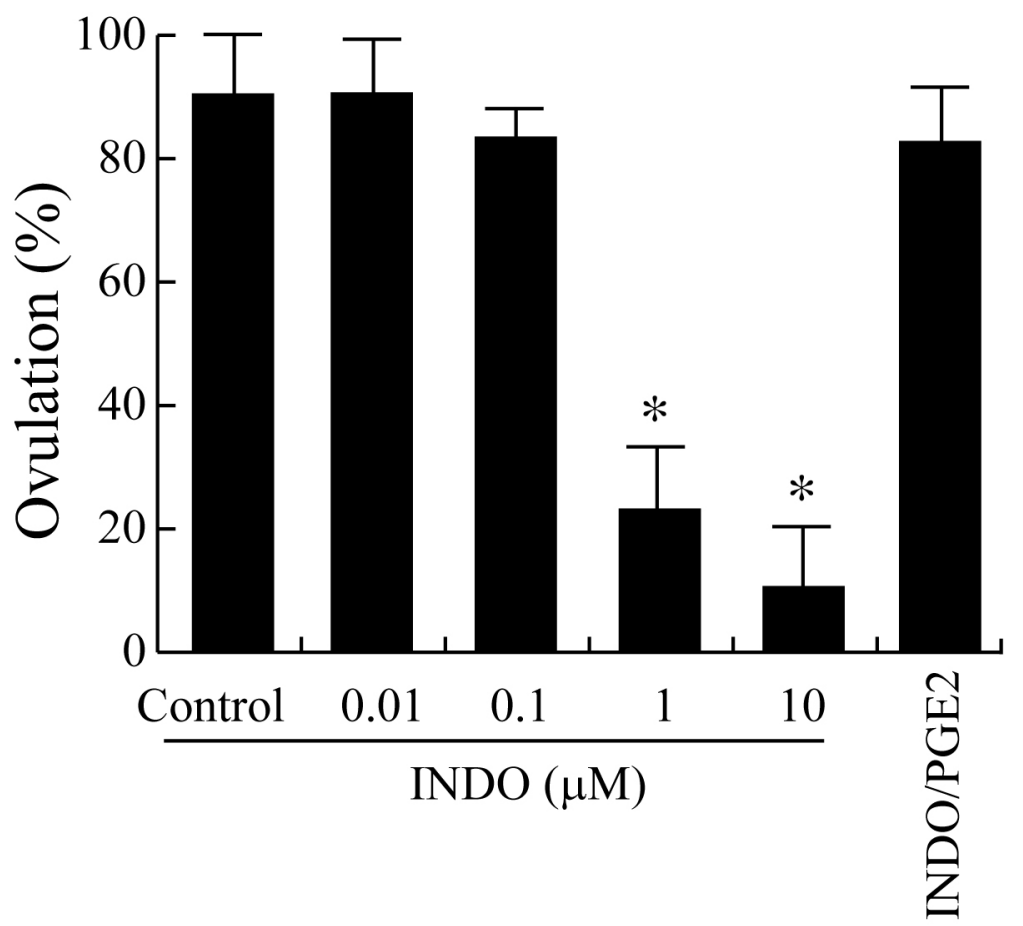

Figure 1 Fujimori et al. 
(A)

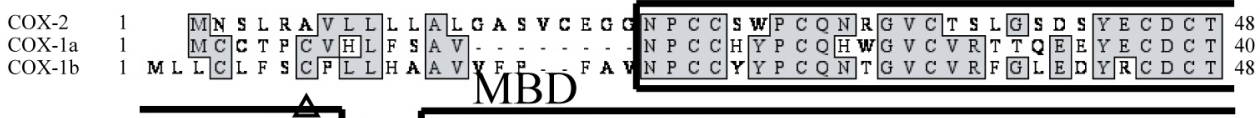
COX-2 49 R T G Y Y Y

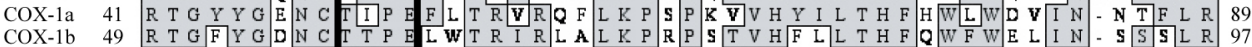

$\operatorname{COX}-2$

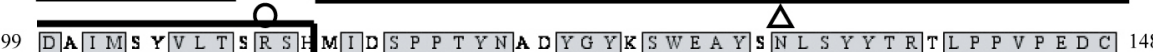

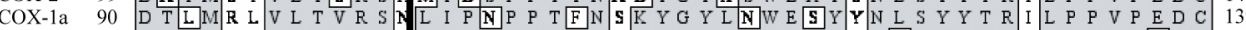
COX-1b 98 D T I M K M M L T V R S

COX-2 149 P T P M G V K G K K E L P N A E E L L E K L L M R R K F I P D P Q G T $\mathbf{L}$ L M F A F F A Q H F T H Q F 198

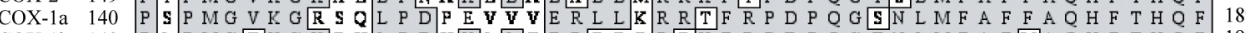

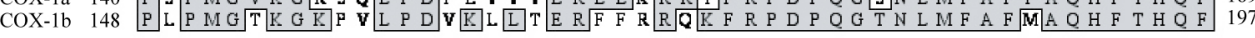

COX-2 199 F K S D M R N G P A F T V A Q G H G V DLL S H I Y G G N L A R O H K L R L F K D G K L K Y O I L N G 248 COX-1a 190 F K T T Y N R M G

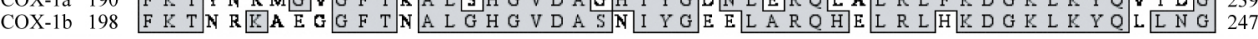

COX-2 249 EVYP P T V K E V G V E M H Y P P H V Q E S Q R F A V G H EA F G L V P G L MMYA T I W L R E H 298 COX-1 240 Q COX-1b 248 E M M P P P T V

COX-2 299 N R V C D V L K E V H P Y Y W D D E COX-1a 290 N R V C D V L K A E H P V W D D E Q L F O T A R L I I I I G E T I

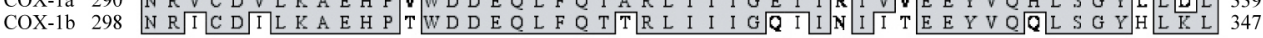

$$
\text { * }
$$

COX-2 349 K F D P E L L F N QR F O Y Q N R I S S E F N T L Y H W H P L M P D S F H I E E K E Y S Y K E F V F 398

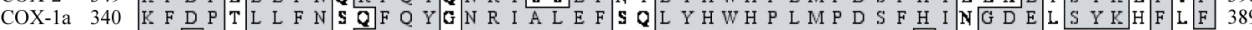

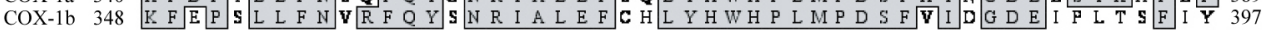

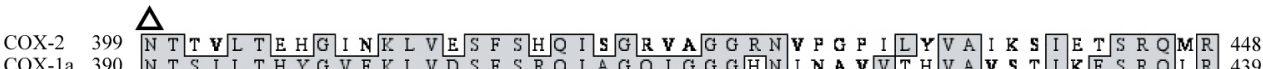

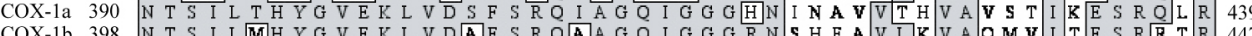
COX-1b 398 N T S I L M H Y G V E K L V D A F S R QAA A G O I G G G R N S H E A V L K V V A Q M V I T E S R R T R 447

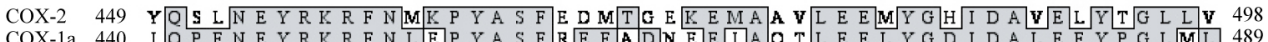

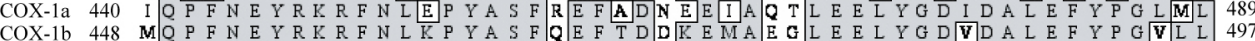
$*$

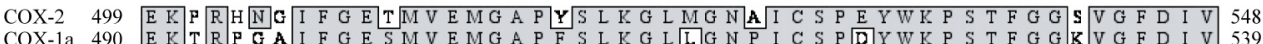

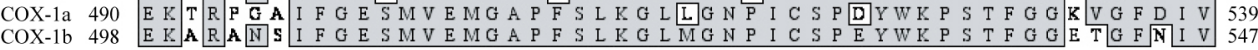

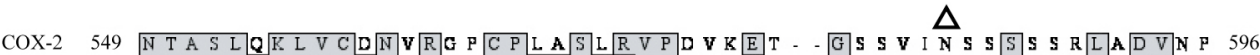

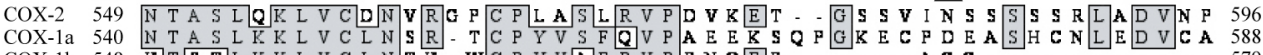

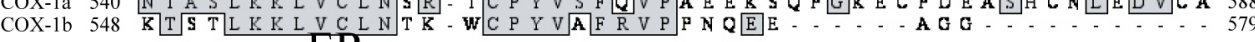

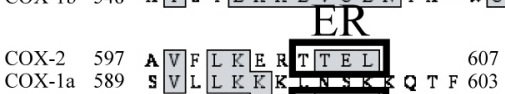

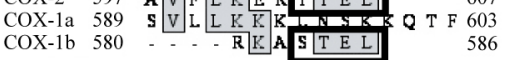

(B)

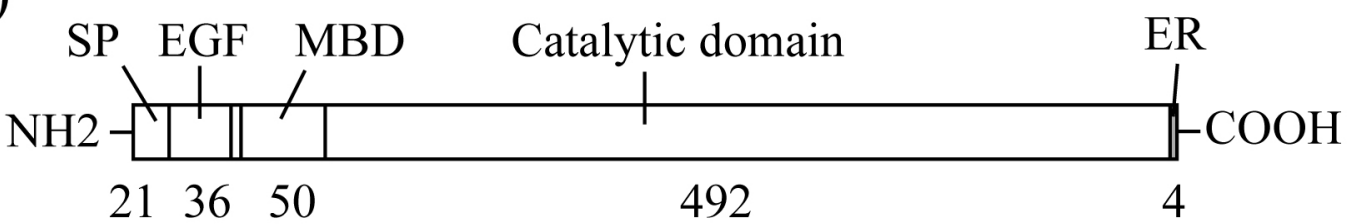

Figure 2 Fujimori et al. 
(A)
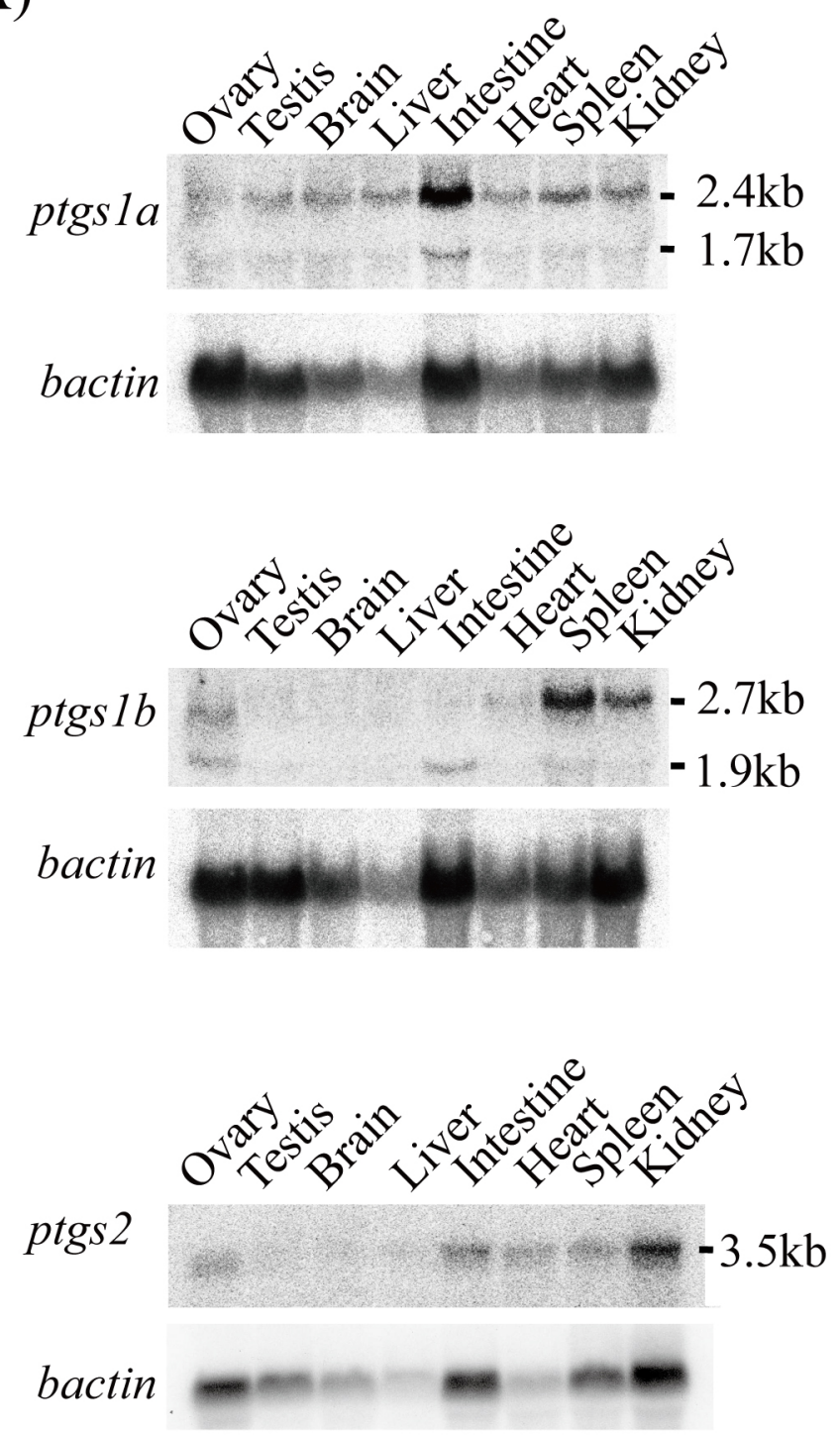

(B)

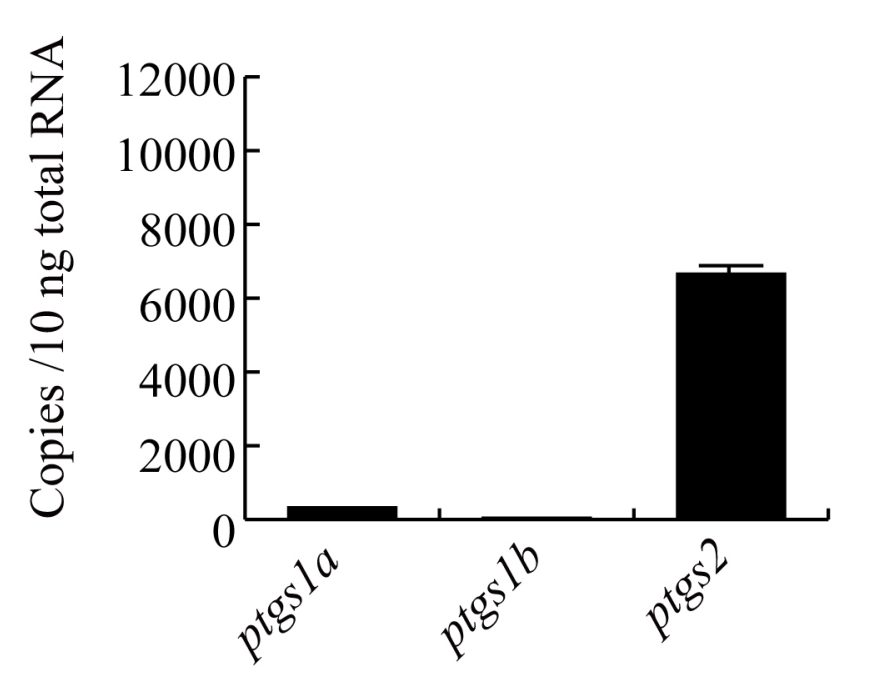

(C)

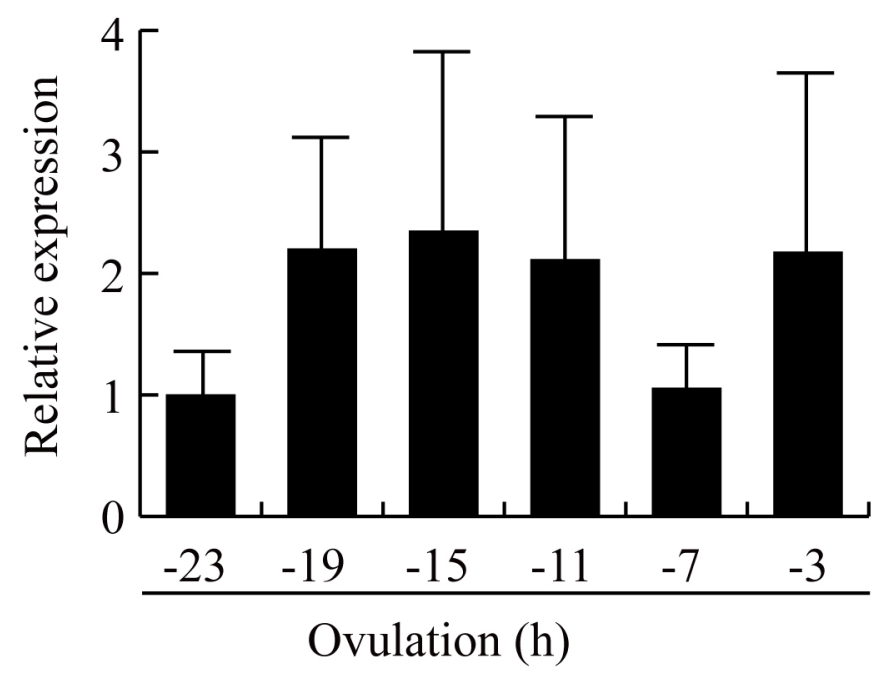

Figure 3 Fujimori et al. 

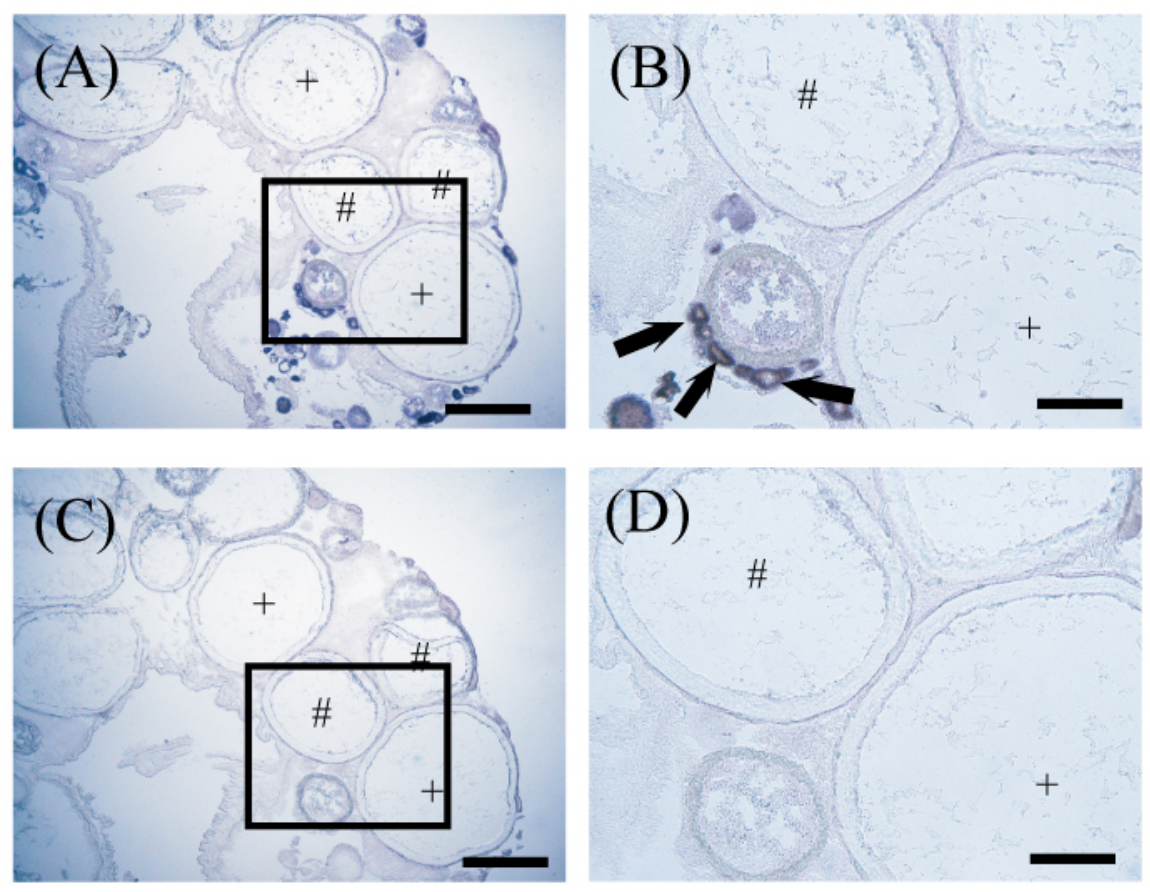

Figure 4 Fujimori et al. 
(A)

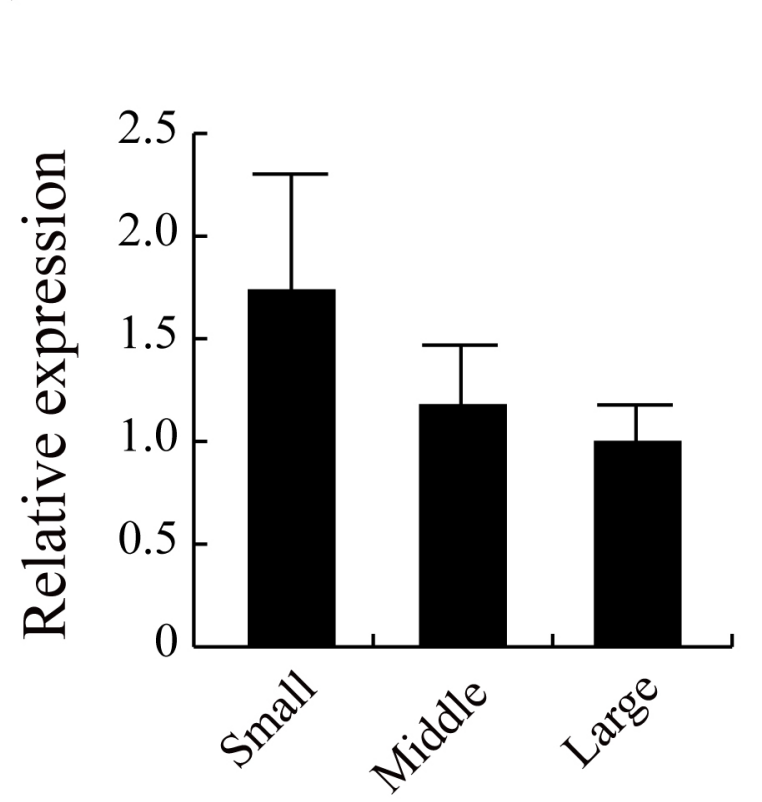

(B)

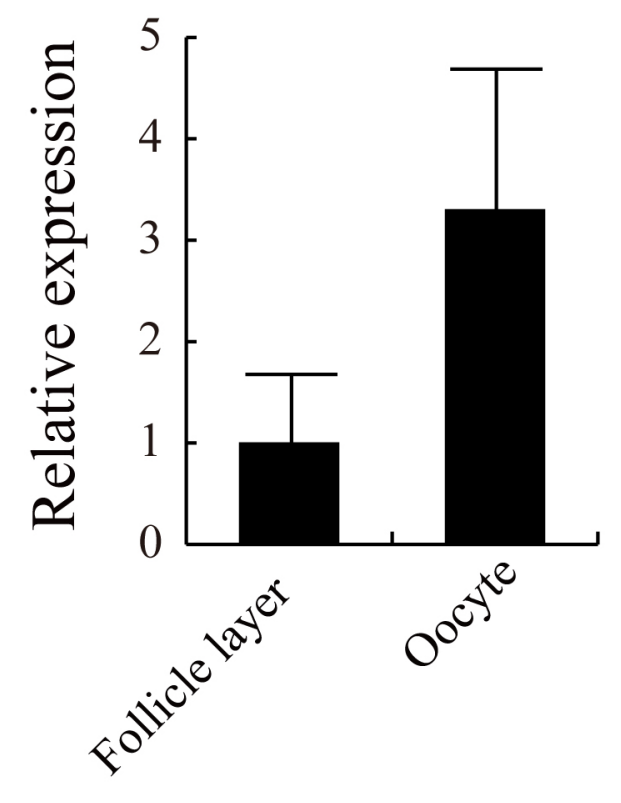

(C)

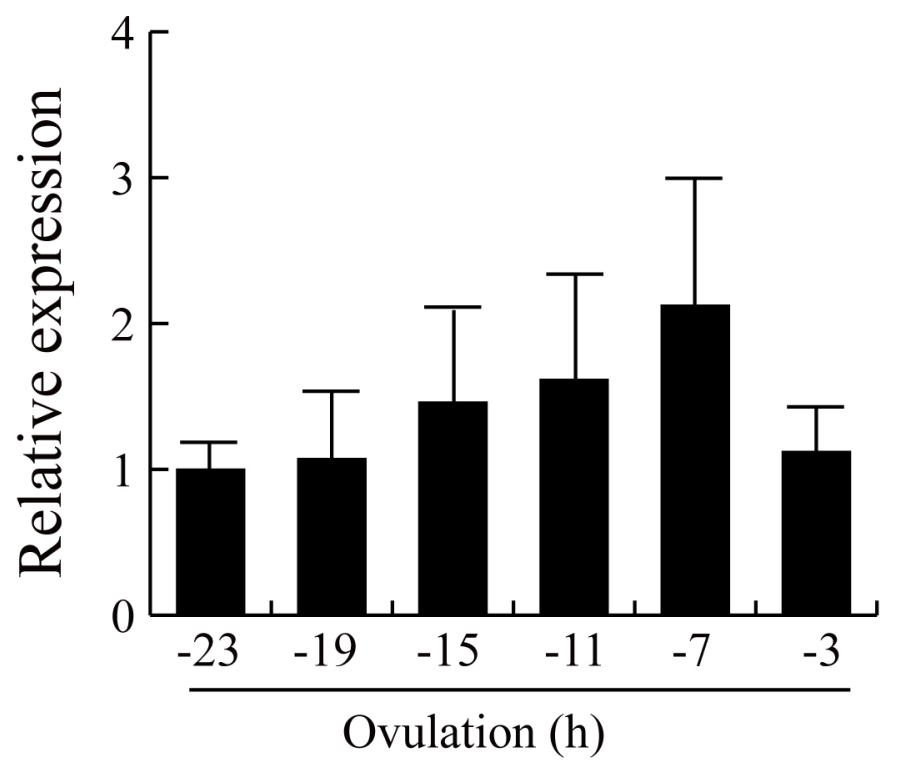

Figure 5 Fujimori et al. 
(A)

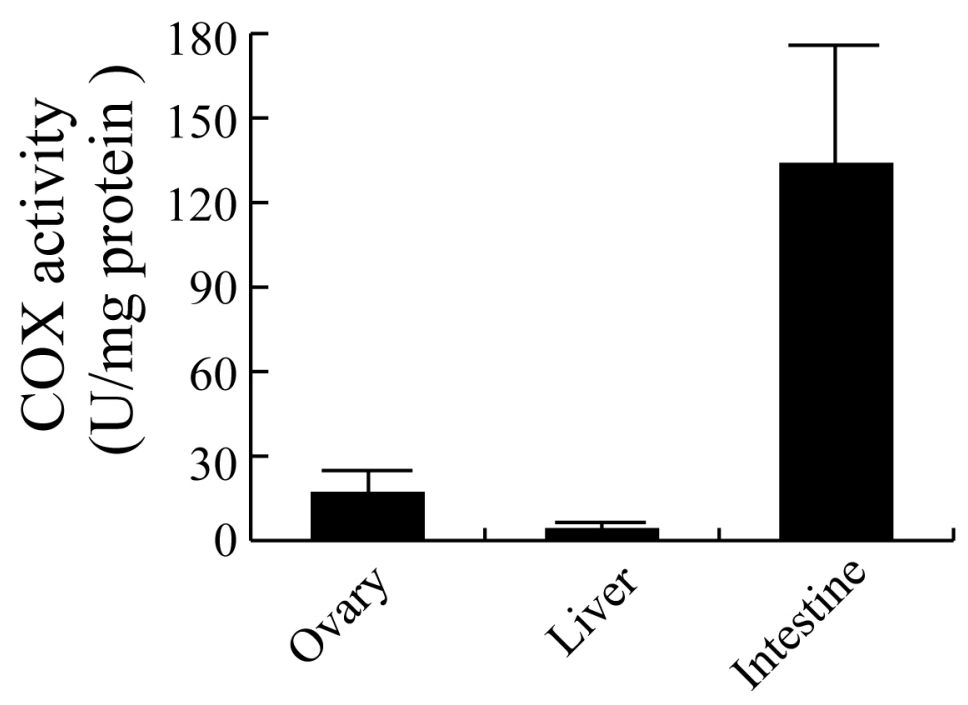

(B)

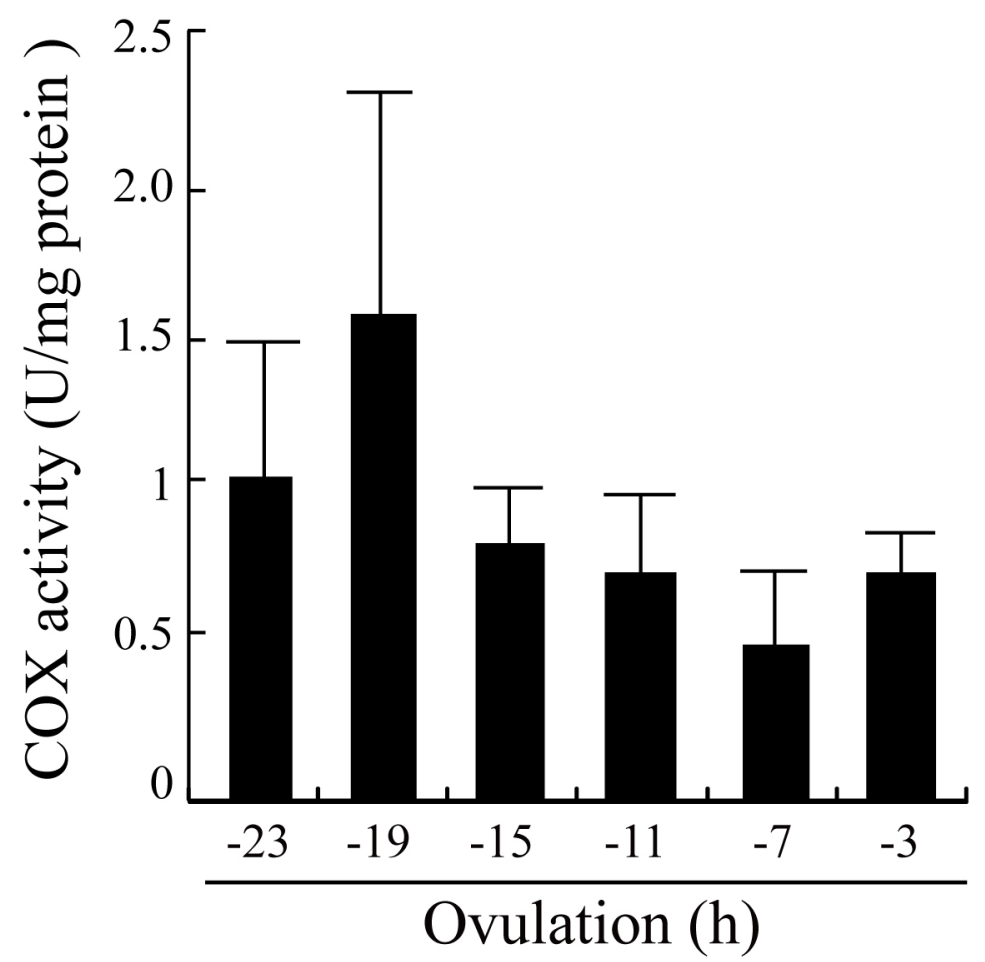

Figure 6 Fujimori et al. 
(A)

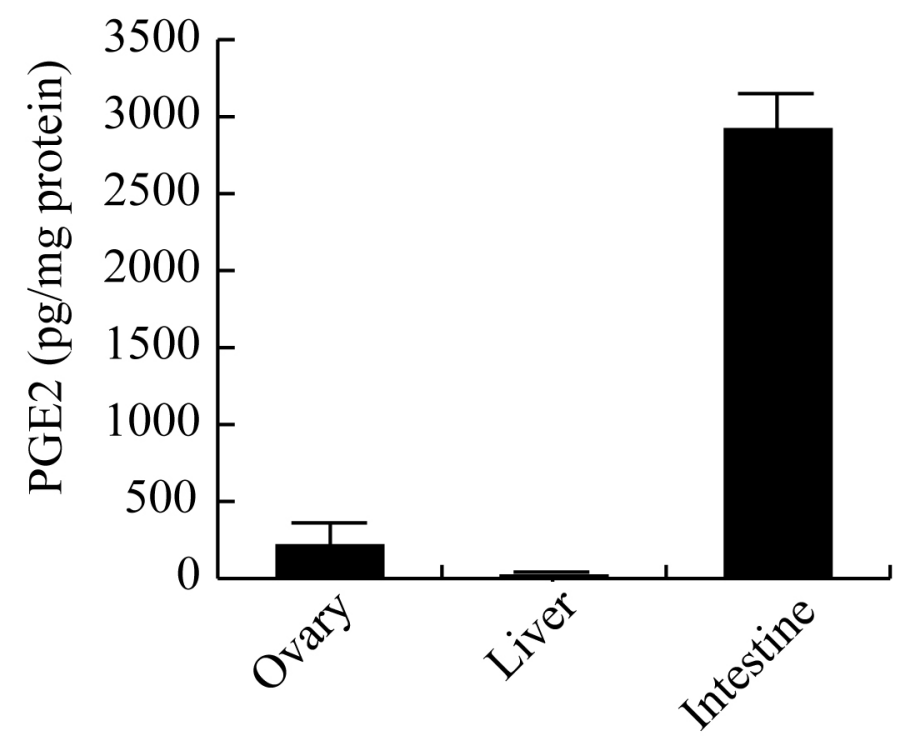

(B)

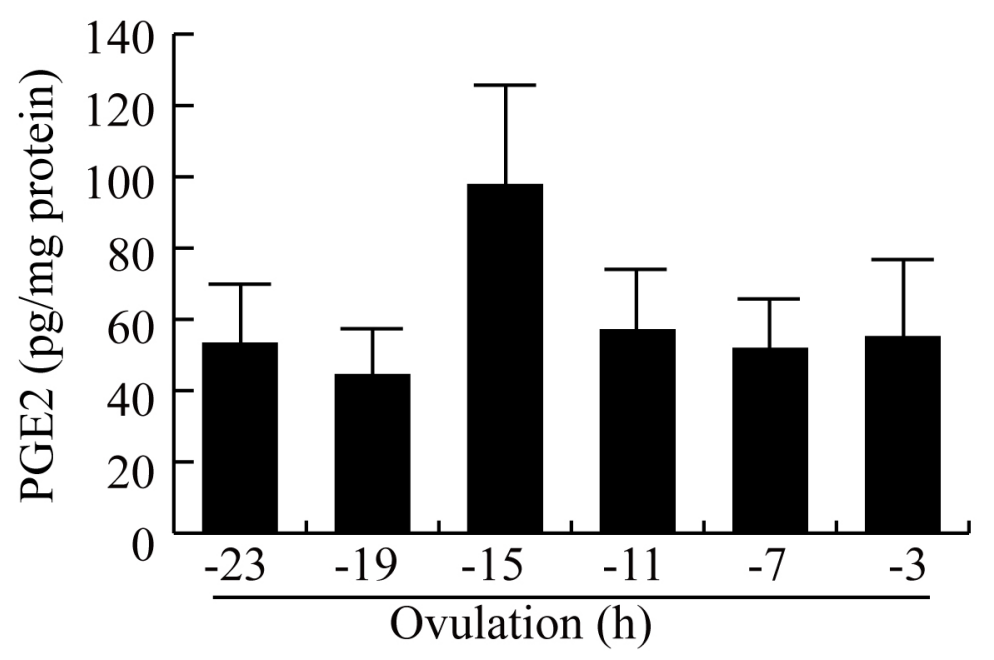

Figure 7 Fujimori et al. 
(A)

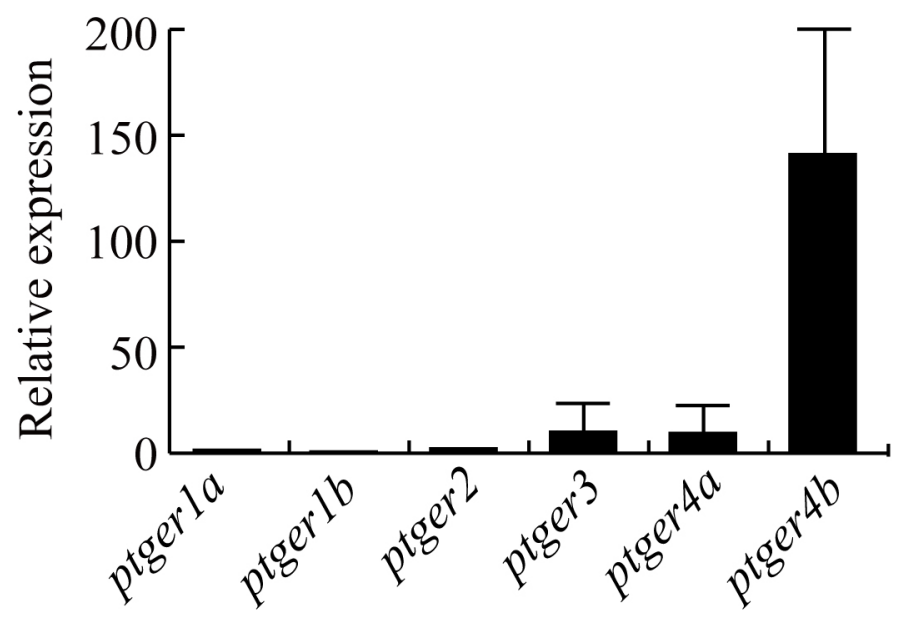

(B)

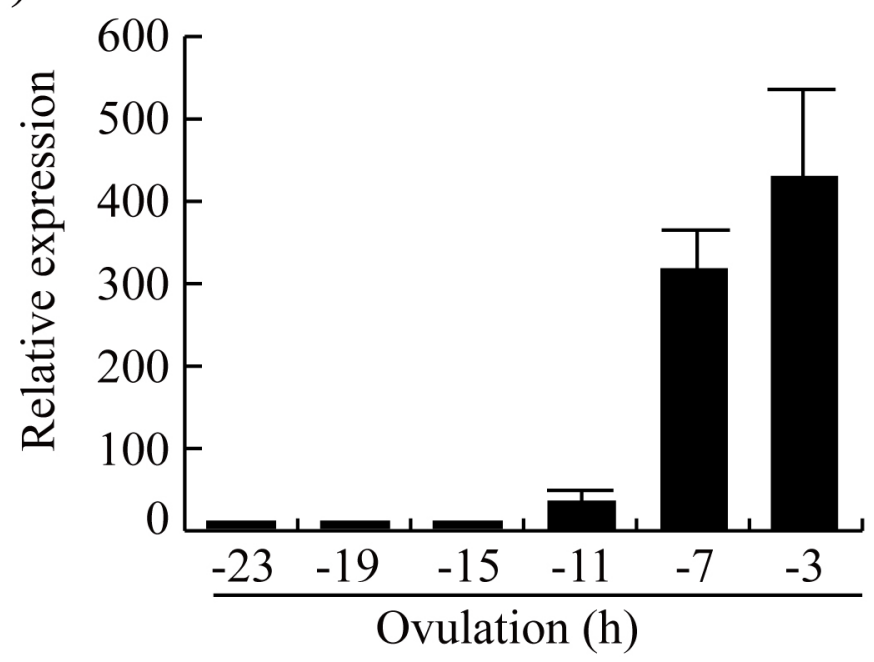

Figure 8 Fujimori et al. 

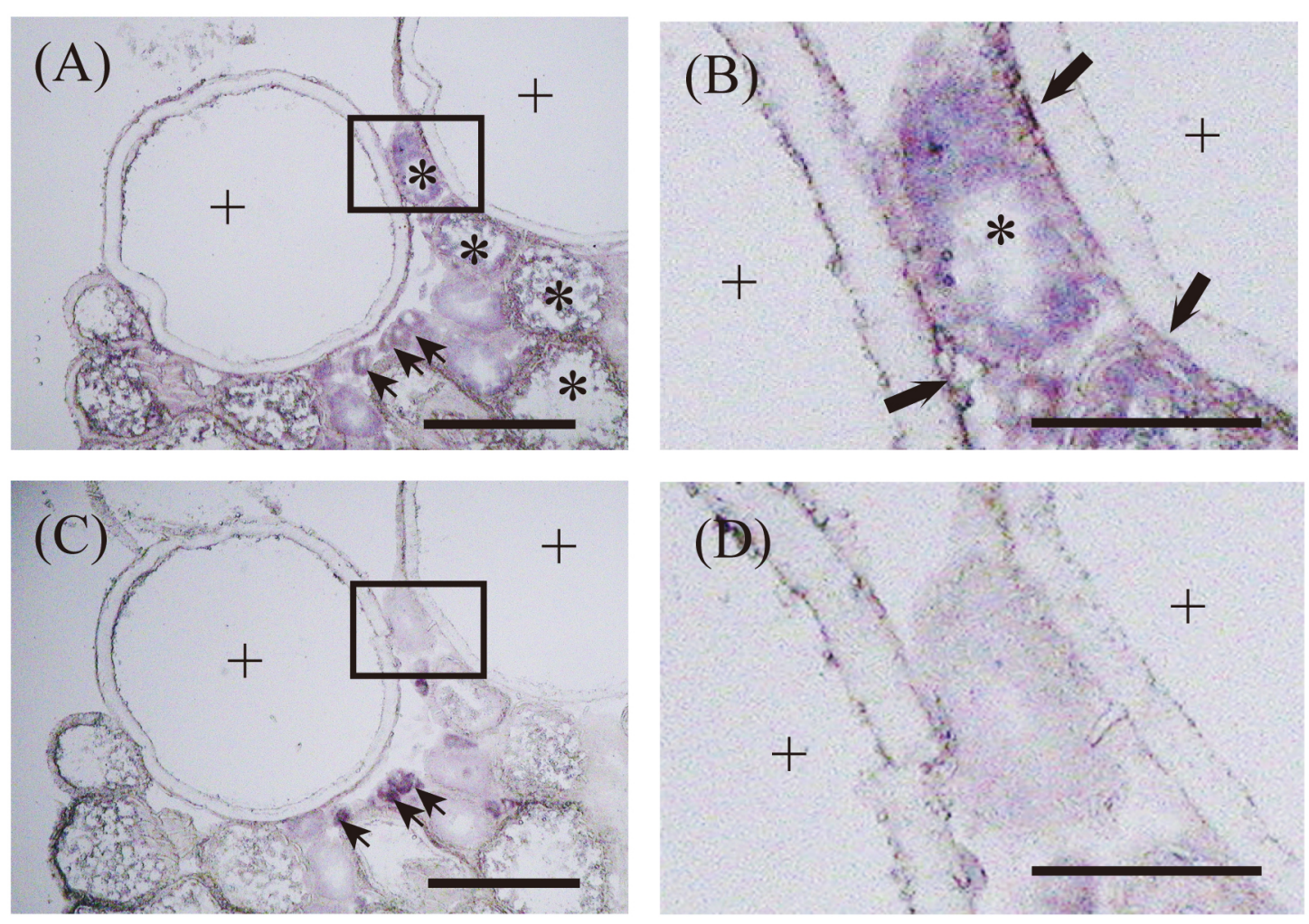

Figure 9 Fujimori et al. 


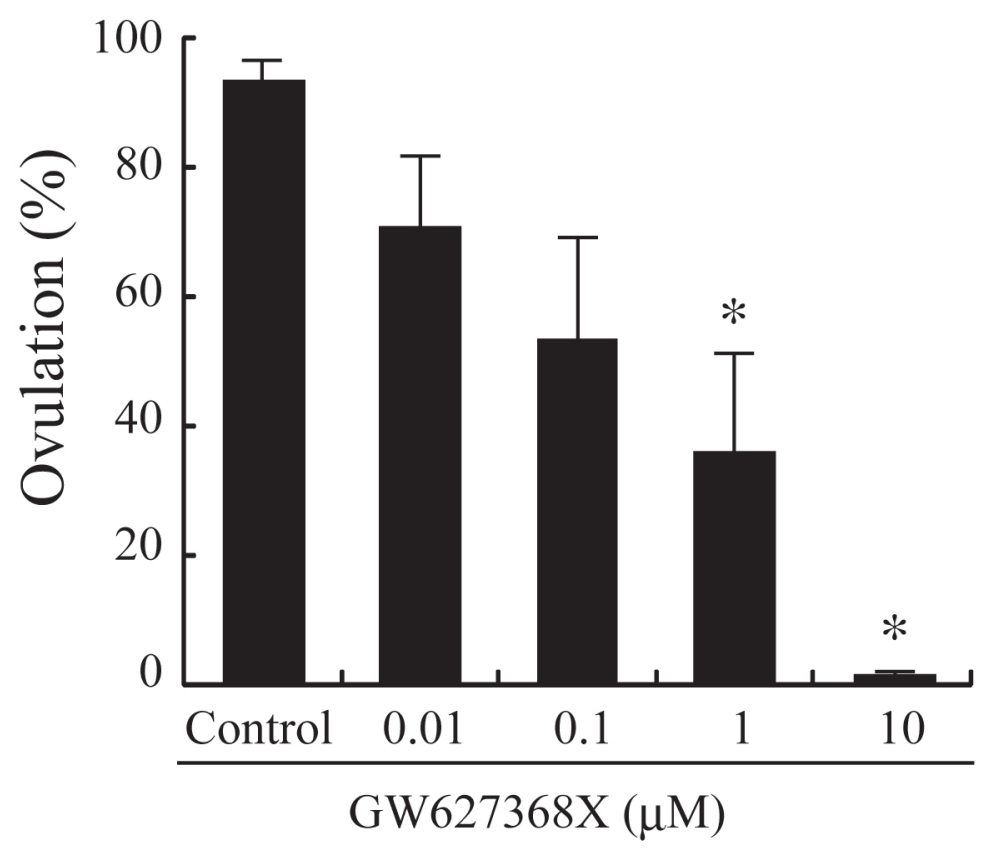

Figure 10 Fujimori et al. 